\title{
CORRELAÇÃO GAMAESPECTROMÉTRICA DE AFLORAMENTOS E POÇOS: ESTUDO DE CASO NA FORMAÇÃO PONTA GROSSA (BACIA DO PARANÁ, BRASIL)
}

\author{
Francisco José Fonseca Ferreira', Ary Gustavo Candido² e Sidnei Pires Rostirolla² \\ Recebido em 8 dezembro, 2008 / Aceito em 18 fevereiro, 2010 \\ Received on December 8, 2008 / Accepted on February 18, 2010
}

\begin{abstract}
In analogue modeling, ground gamma-ray spectrometric data of the Devonian Jaguariaíva, Tibagi, and São Domingos members of the Ponta Grossa Formation (Paraná Basin) allowed for a better understanding of the spatial distribution of lithotypes. Correlations based on gamma-ray values obtained from deep well logging could be improved. Ground values, spaced $50 \mathrm{~cm}$ in sandstones and $100 \mathrm{~cm}$ in shales, were taken along four sections: Arapoti, Tibagi, Jaguariaíva, and Ponta Grossa. The sections were 30,250,12, and 16 meters thickness, respectively. The results show that both ground and deep values reflect the gradual clay enrichment trend noticed along the Arapoti section (transition beds between Furnas and Ponta Grossa formations). Along the Tibagi section (Jaguariaíva Member), total organic carbon values are in direct relation to ground and deep gamma-ray values, and good gamma-ray spectrometric and granulometric correspondence is observed between both deep and ground data along 250 meters of Ponta Grossa Formation outcrops. Along the Jaguariaíva section, clear decrease of intensity is observed in sandy layers, with abruptly lower values at the contacts with basal sandstones of the Itararé Group. Along the Ponta Grossa section, the Tibagi Member, with its notably higher sandfraction content, shows a gamma-ray signature compatible with the coarsening upward observed in well data. The São Domingos Member, a massive clayey interval of the Ponta Grossa Formation, is characterized by high gamma-ray values in both investigation levels. Ground gamma-ray spectrometry combined with detailed outcrop descriptions and deep source data proved to be useful in the establishment of analogue models for the Ponta Grossa Formation in the Paraná Basin.
\end{abstract}

Keywords: ground gamma-ray, gamma-ray well logging, analogue models, Ponta Grossa Formation, Paraná Basin.

RESUMO. No contexto de modelos análogos, dados gamaespectrométricos de superfície da Formação Ponta Grossa (FPG), Devoniano da Bacia do Paraná, constituída pelos membros Jaguariaíva, Tibagi e São Domingos, permitiram melhor entender a distribuição de seus litotipos e estabelecer correlações com os dados de radiação gama derivados de perfis de poços profundos. As medidas de superfície, espaçadas de $50 \mathrm{~cm}$ nos arenitos e $100 \mathrm{~cm}$ nos folhelhos, foram adquiridas em quatro seções: Arapoti, Tibagi, Jaguariaíva e Ponta Grossa, com extensões respectivas de 30, 250, 12 e 16 metros. Os resultados mostraram que a tendência de incremento gradativo da fração argila na seção Arapoti (camadas de transição das formações Furnas e Ponta Grossa) foi bem refletida nos perfis de raios gama em superfície e subsuperfície. No perfil Tibagi (Membro Jaguariaíva), os teores de carbono orgânico total (COT) guardaram relação direta com o aumento da radiação gama em superfície e em profundidade. Ainda neste perfil se constatou relações consistentes dos dados gamaespectrométricos de afloramentos e poços com a seção granulométrica de 250 metros de exposição da FPG. Na seção Jaguariaíva foi possível notar com clareza a diminuição das contagens nas camadas arenosas e a queda abrupta dos valores a partir do contato dos arenitos basais do Grupo Itararé. 0 Membro Tibagi, claramente mais arenoso, explicitou no perfil Ponta Grossa assinatura dos raios gama compatível a um padrão granocrescente ascendente, também verificada nos perfis de poços. 0 Membro São Domingos, representativo de possante intervalo pelítico da FPG, foi também bem caracterizado através de altas contagens nos dois níveis de investigação. 0 emprego de gamaespectrometria de superfície, em correspondência à descrição pormenorizada de afloramentos e a dados de poços profundos, apontou para o estabelecimento de modelos análogos da FPG na Bacia do Paraná.

Palavras-chave: gamaespectrometria de superfície, gamaespectrometria de poço, modelos análogos, Formação Ponta Grossa, Bacia do Paraná.

\footnotetext{
1 Laboratório de Pesquisas em Geofísica Aplicada - LPGA, Curso de Pós-Graduação em Geologia, Departamento de Geologia, Universidade Federal do Paraná, Centro Politécnico, Jardim das Américas, Caixa Postal 19045, 81531-980 Curitiba, PR, Brasil. Tel.: (41) 3361-3132 - E-mail: francisco.ferreira@ufpr.br

2Laboratório de Análise de Bacias e Petrofísica - LABAP, Curso de Pós-Graduação em Geologia, Departamento de Geologia, Universidade Federal do Paraná, Centro Politécnico, Jardim das Américas, Caixa Postal 19045, 81531-980 Curitiba, PR, Brasil. Tel.: (41) 3361-3132 - E-mails: ary_gustavo@hotmail.com; sidnei.rostirolla@vale-ep.com
} 


\section{INTRODUÇÃo}

A utilização de métodos geofísicos é cada vez mais intensa na prospecção de hidrocarbonetos e no estudo de bacias sedimentares. A gravimetria, a magnetometria e a sísmica de reflexão, em geral, possibilitam delinear 0 arcabouço estrutural das bacias e do seu embasamento, enquanto as medidas de perfis geofísicos de poços (elétricos, nucleares e acústicos, e.g. Segesman, 1980; Snyder \& Fleming, 1985) podem se relacionar ao tipo de hidrocarboneto existente nos reservatórios porosos ou fraturados (Ellis \& Singer, 2008). Avanços recentes na aquisição, no processamento e na visualização dos dados de perfis geofísicos de poços têm fornecido informações importantes sobre a variação das propriedades petrofísicas com a profundidade, contribuindo para a caracterização e distribuição espacial das unidades litoestratigráficas e consequente entendimento de seus processos genéticos.

De acordo com Ellis \& Singer (2008), os perfis geofísicos de poços são encarados sob vários enfoques por geólogos, geofísicos e engenheiros (de perfuração, de reservatório e de produção). Do ponto de vista dos ambientes deposicionais, tais perfis podem auxiliar a determinação das sequências estratigráficas e a análise detalhada das fácies de uma formação, a qual envolve sua geometria, estruturas e texturas sedimentares, além da composição (matriz, cimento e tipo de fluido).

Os perfis de raios gama (e.g. Scott et al., 1961; Caldwell et al., 1963; Scott, 1963; Rhodes \& Mott, 1966; Wahl, 1983; Mathis, 1987; Saunders et al., 1987) de afloramentos constituem uma ferramenta simples de correlação com a geologia de superfície (e.g. Aigner et al., 1995). Por outro lado, a gamaespectrometria de poço é largamente empregada na análise estratigráfica, pois permite caracterizar e correlacionar várias superfícies de contato e discordâncias, identificar a natureza e a distribuição lateral e vertical de camadas, delinear as tendências de granocrescência/granodecrescência das rochas sedimentares, além de contribuir na caracterização de reservatórios de hidrocarbonetos (e.g. Svendsen \& Hartley, 2001).

Com base nas premissas anteriores, o trabalho mostra a aplicação do método gamaespectrométrico em superfície, a partir de medições em afloramentos da Formação Ponta Grossa (Devoniano da Bacia do Paraná), com ênfase nos arenitos de sua porção média (Membro Tibagi), no sentido de melhor entender a distribuição de seus litotipos e estabelecer correlações qualitativas simplificadas aos dados de poços profundos perfurados na bacia, na perspectiva de modelos análogos, constituindo o principal objetivo da presente pesquisa. Entretanto, Dypvik \& Eriksen (1983) já chamavam a atenção para as dificuldades de correlações simplificadas, questionando o conceito amplamente aceito de que as argilas denotam altas radioatividades, em contraste às reduzidas contagens dos arenitos, citando que as argilas bentoníticas, por exemplo, exibem teores tão baixos quanto os arenitos. North \& Boering (1999) também relataram dificuldades do uso de dados gamaespectrométricos para discriminar fácies em pacotes flúvio-eólicos interdigitados e interpretar seus ambientes deposicionias. Do mesmo modo, conforme Rider (1990), em sequências continentais, as correlações baseadas apenas nos padrões gamaespectrométricos da contagem total (CT) não se prestam à análise textural de arenitos, estimativas granuIométricas dos estratos (percentual de argilas) e caracterização de fácies sedimentares. Mesmo considerando tais limitações, 0 estudo pormenorizado de afloramentos pode aprimorar o conhecimento de estratos equivalentes em subsuperfície (e.g. Koehrer et al., 2010), normalmente carente de dados petrofísicos diretos, como a Formação Ponta Grossa, que ocorre em profundidades superiores a 3.500 metros na denominada calha central da Bacia do Paraná (Milani, 1997). Recentemente, levantamentos gamaespectrométricos de exposições da Formação Prosperança (Proterozóico Superior, Grupo Purus), borda Norte da Bacia do Amazonas, foram apresentados por Carvalho et al. (2006) e Rudnitzki et al. (2007).

\section{REVISÃO DA LITERATURA \\ Gamaespectrometria}

A gamaespectrometria (aérea, terrestre e de poço) é baseada nos princípios da geofísica nuclear. Como se sabe, existem três tipos de partículas provenientes de núcleos instáveis de substâncias radioativas: $\alpha$ (fluxos de partículas carregadas positivamente, compostas por dois nêutrons e dois prótons, ou seja, núcleos de hélio. São muito ionizantes, porém com pouca penetração); $\beta$ (fluxos de partículas da mesma natureza dos elétrons orbitais, resultantes da desintegração de nêutrons do núcleo. São mais penetrantes, porém menos ionizantes que as radiações $\alpha$ ) e $\gamma$ (ondas eletromagnéticas, o tipo de radiação mais penetrativa, do que decorre 0 interesse para a geofísica aplicada. Como não apresentam carga elétrica, não são desviadas por campos elétricos e magnéticos como as duas partículas anteriores). A unidade é o elétron-volt (eV), equivalente a energia cinética adquirida por um elétron sob a ação do potencial de um volt. Entretanto, em gamaespectrometria, são utilizadas unidades derivadas como milhões de elétrons-volts (MeV), ou quiloelétrons-volts (keV).

Quando 0 núcleo de um átomo emite uma partícula $\alpha$, uma partícula $\beta$, um raio $\gamma$, ou então quando captura um elétron de uma camada externa ao núcleo, o processo é chamado de 
decaimento radioativo (Arya, 1966). 0 decaimento radioativo é um fenômeno estatístico, resultante de um grande número de eventos, sujeitos a lei da probabilidade (Kaplan, 1962). Para apresentar a descrição estatística da radioatividade, Wehr \& Richards Jr. (1965) levaram em conta que no instante $t=0$ existam $N_{o}$ átomos radioativos. Considerando a presença de $N$ átomos em qualquer instante posterior $t$, a quantidade provável que se desintegrará na unidade de tempo será $\lambda N$, representando $\lambda$ a probabilidade de um átomo se desintegrar na unidade de tempo (constante de decaimento). Como cada desintegração reduz o número $N$, pode-se então representar as prováveis desintegrações por unidade de tempo (ou atividade) por $-d N / d t=\lambda N$, ou $d N=-\lambda d t N$. Esta equação, segundo Arya (1966), mostra que o número de decaimentos no tempo é proporcional à abundância de átomos $(N)$, ao intervalo de tempo $d t$ e a constante de decaimento $\lambda$ (característica de cada radioisótopo). 0 sinal negativo significa que $N$ decresce quando $t$ cresce. Assumindo-se que no instante $t=00$ número de átomos radioativos é $N_{o}$, e integrando-se a equação anterior, têm-se 0 número de átomos radioativos presentes em um tempo $t, 0$ qual pode ser representado pela seguinte equação: $N(t)=N_{o} e^{-\lambda t}$. Uma grandeza de importância no estudo da radioatividade é a meia-vida. Também representada por $t_{1 / 2}$ ou $T$, esta variável é definida como o intervalo de tempo requerido para que o número inicial de átomos se reduza pela metade, ou seja, $t_{1 / 2}=0,693 / \lambda$.

Em gamaespectrometria três são os principais processos segundo os quais a radiação gama interage com a matéria (e.g. Ellis \& Singer, 2008): efeito fotoelétrico, espalhamento Compton e produção de par. A probabilidade de ocorrência da interação de um raio gama depende do número atômico da substância e da energia incidente. No efeito fotoelétrico, o raio gama é completamente absorvido e transfere sua energia para um elétron periférico, o qual é expelido do átomo. É um processo de absorção característico de baixos níveis energéticos (menores que 100 keV). 0 espalhamento Compton ocorre em níveis energéticos moderados e envolve a interação dos raios gama com os elétrons, na qual um fóton perde parte de sua energia para um elétron e é desviado segundo um ângulo relacionado à sua direção original de incidência. A perda de energia do raio gama é transferida, por energia cinética, para um elétron. Como a maioria dos materiais naturais objeto de medidas gamaespectrométricas denota baixos números atômicos (entre 10 e 20) e energias médias, 0 espalhamento Compton é o processo de interação que predomina no detector. Na produção de par o fóton incidente se relaciona com o campo elétrico do núcleo e é completamente absorvido, resultando em um par elétron-pósitron com energia equivalente ao fóton original, ocorrendo em níveis superiores a 1,02 MeV, particularmente em materiais de elevado número atômico (maior que 30).

De forma simplificada, a detecção dos raios gama se processa em duas etapas (Ellis \& Singer, 2008): na primeira, os raios gama, em contato com o detector, são parcial ou totalmente convertidos em radiação ionizante (elétrons), onde ocorrem os três tipos de interação antes descritos, e na segunda a energia dos elétrons é transformada em sinais. Apesar da existência de outros tipos de detector (gás ionizante e estado sólido, e.g. Ellis \& Singer, 2008), os cristais de cintilação são os mais empregados em gamaespectrometria. Tais cristais, normalmente constituídos de iodeto de sódio contaminado por tálio, Nal(TI), são sensíveis a radiação ionizante e emitem luz, cujos flashes são reconhecidos por um fotomultiplicador acoplado ao cristal e transformados em pulsos elétricos. A grande vantagem deste tipo de detector, cuja eficiência depende essencialmente do volume e da densidade, é discriminar os níveis energéticos dos raios gama. Entretanto, de acordo com Ellis \& Singer (2008), as medidas do espectro dos raios gama são afetadas pelos processos físicos que ocorrem durante os registros. Assim, somente nos casos em que os raios gama sejam totalmente absorvidos, é possível estabelecer relações de proporcionalidade dos pulsos elétricos e a energia da radiação.

Da mesma forma que na gamaespectrometria aérea e terrestre, dois tipos de instrumento são normalmente utilizados nos poços: os cintilômetros, que medem a energia ou contagem total (CT) e os gamaespectrômetros que permitem discriminar a energia e quantificar os radioisótopos, os quais devem ser previamente calibrados (transformações das contagens por segundo em concentrações).

A gamaespectrometria mede as contagens/concentrações da CT, K, eU e eTh em rochas, sedimentos e solos através da detecção dos raios gama emitidos durante 0 decaimento radioativo natural destes elementos, em particular os seguintes (e.g. Faure, 1986): ${ }^{40} \mathrm{~K}$, que representa $0,01167 \%$ do $\mathrm{K}$ total $\left({ }^{39} \mathrm{~K}\right.$ e ${ }^{41} \mathrm{~K}$, não são radioativos e representam, respectivamente, 93,2581\% e $6,7302 \%$ do K total), ${ }^{238} \mathrm{U}\left(99,2743 \%\right.$ do U total), ${ }^{235} \mathrm{U}(0,7200 \%$ do $\mathrm{U}$ total), ${ }^{234} \mathrm{U}\left(0,0057 \%\right.$ do $\mathrm{U}$ total), e ${ }^{232} \mathrm{Th}$ (praticamente $100 \%$ do Th total). Uma revisão detalhada sobre 0 comportamento geoquímico, abundância, principais minerais, propriedades cristaloquímicas e mobilidade durante 0 intemperismo e a diagênese de K, U e Th foi recentemente apresentada por Ulbrich et al. (2009).

A gamaespectrometria de poço, tradicionalmente, é utilizada para correlacionar estratos, identificar preliminarmente os tipos 
litológicos e estimar grosseiramente o volume de folhelhos ( $V_{c l}$, Ellis \& Singer, 2008). Tais autores referem que 0 uso dos perfis para prever a argilosidade (shaliness) de uma formação tem suscitado problemas, uma vez que os termos argila e folhelho são utilizados indistintamente na literatura, apesar de ambos encerrarem concentrações de radioisótopos. Ellis \& Singer (2008) citam que um procedimento usual para avaliar a fração de volume dos folhelhos, ou argilosidade, de uma formação $\left(V_{s h}\right)$ é identificar nos logs o valor mínimo (clean point, $\gamma_{\min }, 0 \%$ de folhelho) e máximo ( shale point, $\gamma_{\max }, 100 \%$ de folhelho). Desta maneira, é possivel determinar os valores em qualquer ponto de perfil $\left(\gamma_{\text {log }}\right)$ e proceder à conversão através de um índice linear, IGR $=\left(\gamma_{\log }-\gamma_{\min }\right) /\left(\gamma_{\max }-\gamma_{\min }\right)$. Este índice pode ser expresso em porcentagem de argilosidade, através do uso de várias cartas, de acordo com a litologia. Gráficos de correlação do K (\%) versus eTh (ppm) são frequentemente utilizados para estimar 0 volume de folhelhos e separar os arenitos micáceos dos arenitos argilosos (Hodson et al., 1976), assim como identificar vários minerais (biotita, muscovita, glauconita, illita, carbonatos, caulinitas montmorillonita, bentonita, bauxita, Ruhovets \& Fertl, 1982). Na gamaespectrometria de poço, ênfase é dada as medidas de radioatividade dos isótopos em folhelhos, as quais se vinculam ao tipo e ao volume de minerais de argila contidos nas rochas sedimentares. A retenção de cátions radioativos nas argilas se deve a sua capacidade de troca catiônica (CTC, e.g. Costa et al., 1999), a qual é variável (e.g. caolinita, illita, esmectita, respectivamente, 3-5, 10-40, 80-150 meq/100g). Os minerais de argila são responsáveis por duas fontes principais de radioatividade nos perfis de poços: potássio e tório (Ellis \& Singer, 2008). Os autores comentam que além do potássio do grupo da illita, este elemento ocorre no grupo da montmorillonita, em adição as micas (biotita e muscovita). Como decorrência da mencionada CTC, os minerais de argila retêm elementos-traço como 0 tório, que é praticamente insolúvel e de baixa mobilidade. Pelo contrário, 0 urânio, pela sua grande solubilidade, é facilmente transportado das argilas e fixado em matéria orgânica, cuja CTC é muitas vezes maior que a das argilas (e.g. Resende et al., 2002, Becegato \& Ferreira, 2005). Portanto, em geral, se observa forte correlação de altas concentrações de potássio e tório em minerais de argila, também decorrentes da contribuição de outros minerais, como os feldspatos, enquanto a correlação ao urânio é desprezível pelas razões apontadas. Segundo Ellis \& Singer (2008), é comum somar os teores de tório e potássio, diretamente vinculados às argilas, desta forma separando as frequentes flutuações do urânio. Citam também que 0 entendimento das propriedades físicas das argilas é de grande importância para pressupor as reservas e a produção de hidrocarbonetos, além de auxiliar as estimativas da porosidade, da saturação e da permeabilidade de reservatórios.

\section{Gamaespectrometria de afloramentos e poços}

Embora escassos no Brasil, os trabalhos dedicados a medições gamaespectrométricas de afloramentos e sua correlação com dados análogos de poços são comuns na literatura internacional (e.g. Slatt et al., 1992, 1995; Alsharhan et al., 1993; Aigner et al., 1995, 1996, 2007; Bessa \& Hesselbo, 1997; Ahmadi \& Coe, 1998; Hornung \& Aigner, 1999, 2002a, b; North \& Boering, 1999; Forst et al., 2000; Hadley et al., 2000; Lüning et al., 2000a,b, 2004, 2005; Svendsen \& Hartley, 2001; Brown, 2002; Filer, 2002; Martinius et al., 2002; Brachert et al., 2003; Chiozzi et al., 2003; Hladil et al., 2003; Lüning \& Kolonic, 2003; Pawellek \& Aigner, 2003, 2004; Szurlies et al., 2003; Vennin et al., 2003; Doveton \& Merriam, 2004; Gehring, 2004; Kostic \& Aigner, 2004; Ruf \& Aigner, 2004; Collins et al., 2006; Schnyder et al., 2006; Betzler et al., 2007; Evans et al., 2007; Koehrer et al., 2010).

Slatt et al. (1992), com base na comparação de dados radiométricos de afloramentos e poços do Grupo Jackfork, Arkansas (USA), revelaram que os primeiros foram úteis para 0 entendimento da geometria e das mudanças laterais de fácies de turbiditos em campos de hidrocarbonetos (óleo e gás). Em trabalho posterior, Slatt et al. (1995) relataram novos estudos em afloramentos de formações cretáceas (Almond, Graneros e Niobrara) no Colorado (USA) e da Formação Green River (Eoceno), em Wyoming (USA), os quais foram considerados bons exemplos para se conformarem a dados de radioatividade de poços.

Alsharhan et al. (1993), tendo em vista controvérsias na literatura sobre a distribuição de camadas glaciais do Paleozóico Superior na Península Arábica e a descoberta de petróleo na Formação Al Khlata, definiram em superfície 10 litofácies na região de Oman e interpretaram seus ambientes deposicionais, os quais indicaram boa correlação com perfis de raios gama e de densidade de poços, na perspectiva de prever novas ocorrências de hidrocarbonetos. Constataram, com base em dados de aproximadamente 500 perfurações, a continuidade das fácies glaciais (diamictitos) em subsuperfície e discutiram seu potencial econômico.

Aigner et al. (1995), a partir do arcabouço de sequências estratigráficas do Triássico da Alemanha definidas por Aigner \& Bachmann (1992), apresentaram resultados de correlação radioativo-geológica de afloramentos e poços em três áreas-alvo. Os dados de campo foram coletados em contagens por segundo (cps), com intervalos de amostragem de 5 e $10 \mathrm{~cm}$ e tempos de 
integração de 2, 5 e 10 s. Em uma das áreas-alvo, numa exposição de 32 metros, mostraram que as assinaturas radioativas de ciclos retrogradacionais e progradacionais, em escala métrica, podem contribuir para a interpretação e correlação de perfis de poços separados por grandes distâncias. No outro exemplo, em afloramento de 36 metros, demonstraram que os dados de radiação gama são controlados pela quantidade de argilitos, sulfatos e carbonatos. No último estudo de caso, em seção de 15 metros de antiga planície aluvionar, ressaltaram também a importância da calibração radioativa de afloramentos para o melhor entendimento da distribuição das camadas em subsuperfície, muitas vezes não identificadas claramente nos perfis de poços. Concluíram que a gamaespectrometria de afloramentos fornece subsídios para o estudo quantitativo de aquíferos e reservatórios de hidrocarbonetos análogos.

Bessa \& Hesselbo (1997) realizaram 501 conjuntos de leituras espectrais, separados de $30 \mathrm{~cm}$, tempo de integração variando de $240 \mathrm{~s}$ (folhelhos) a $480 \mathrm{~s}$ (calcários), distribuídos ao longo de $164 \mathrm{~m}$ de afloramentos em várias localidades do Sudoeste da Inglaterra. Os dados foram subdivididos em dois grupos: Bacia de Bristol Channel e Bacia de Wessex. Identificaram 10 e 9 unidades gamaespectrométricas, respectivamente, com base nas variações de CT, K, eU, eTh, eTh/eU e eTh/K, as quais foram posteriormente integradas a informações lito- e bioestratigráficas. Na Bacia de Bristol Channel verificaram que os ciclos sedimentares, definidos independentemente pela geologia e pela bioestratigrafia, coincidiram com unidades radiométricas. Na Bacia de Wessex (Jurássico Superior), citaram que a definição de uma sucessão estratigráfica completa baseada apenas na CT é insuficiente, uma vez que os incrementos de $\mathrm{K}$ e Th são compensados por baixos teores de U. Os dados geofísicos também permitiram delinear ciclos sedimentares subordinados, com espessura média de $270 \mathrm{~cm}$, os quais podem não ser percebidos no campo em função de similaridades litológicas. Em adição, na ausência de dados bioestratigráficos, sugeriram que as informações radiométricas de afloramentos podem facilitar a calibração dos logs dos poços e ensejar, como consequência, reinterpretações da litoestratigrafia de subsuperfície.

Ahmadi \& Coe (1998) relacionaram dados radiométricos e de densidade de afloramentos (medidas espaçadas de 30-40 cm) com os de 11 poços separados de 0,5 a 170 km, também da Bacia Wessex (Inglaterra), concluindo que os intervalos das variáveis são compatíveis em ambos os níveis de investigação (15-140 API e $\left.1,8-2,9 \mathrm{~g} / \mathrm{cm}^{3}\right)$.

Hornung \& Aigner (1999), com base em dados petrofísicos e sedimentológicos de afloramentos, estudaram um sistema de planície aluvial distal da Bacia de Keuper (Triássico Superior, Sudoeste da Alemanha), visando aperfeiçoar a interpretação de estratos análogos em subsuperfície (reservatórios de hidrocarbonetos e aquíferos), localizados cerca de $100 \mathrm{~km}$ a Sudoeste da área de estudo. As medidas radiométricas foram adquiridas com espaçamento de $20 \mathrm{~cm}$ (preferencialmente na forma de rapel), distribuídas em área superior a $20.000 \mathrm{~m}^{2}$ de cinco afloramentos e pedreiras. Em adição, amostras separadas no máximo de $50 \mathrm{~cm}$ foram obtidas por perfurações horizontais para determinação da permeabilidade e da porosidade. Definiram 14 litofácies e 9 grupos de elementos da arquitetura do sistema. Constataram que não foi possível separar, a partir dos dados radiométricos e de permo-porosidade, em função da dispersão dos valores, as litofácies características do sistema fluvial. Entretanto, notaram correlação inversa dos raios gama com a porosidade e a permeabilidade, permitindo a distinção de rochas com cimentos argilosos e carbonáticos. Concluíram que os 9 grupos anteriores foram quantitativamente caracterizados pelos dados radiométricos e de permo-porosidade, e que os primeiros foram de grande valia para calibrar a interpretação dos raios gama em subsuperfície.

Hornung \& Aigner (2002a,b) ampliaram a pesquisa anterior, na mesma sequência continental clástica, incluindo, além de dados de subsuperfície (mais de 60 poços), $2.000 \mathrm{~m}$ de perfis GPR (Ground Penetrating Radar), 4.500 medidas gamaespectrométricas, 1.860 de permeabilidade e 1.360 de porosidade, com 0 intuito de caracterizar os padrões de fluxo e compará-los a reservatórios análogos como os do Mar do Norte e da Bacia de Paris. As 14 litofácies antes reconhecidas por Hornung \& Aigner (1999), foram classificadas em quatro grupos com propriedades petrofísicas similares. A concepção de um modelo 3-D da permo-porosidade, calcado na integração de dados geológicos e geofísicos (radiométricos e de radar), permitiu tecer inferências sobre a geometria e as dimensões das cinco unidades de fluxo reconhecidas, incluindo as barreiras. Por fim, com base nas informações dos afloramentos e pedreiras, distribuídas em área superior a $80.000 \mathrm{~m}^{2}$, os autores elencaram critérios que podem auxiliar as simulações de fluxo em reservatórios análogos profundos.

Para interpretar corretamente perfis de poços, North \& Boering (1999) efetuaram medidas espectrais detalhadas de K, eTh e eU em exposição de cerca de $50 \mathrm{~m}$ de uma sucessão fluvio-eólica do Grupo Cutler, Sudeste de Utah (USA), em correspondência a estudos sedimentológicos e petrológicos. 0 intervalo usual de amostragem foi de $15 \mathrm{~cm}$, chegando a $100 \mathrm{~cm}$ em espessos pacotes eólicos, nos quais as variações radiométricas não foram significativas. 0 tempo de integração das leituras, normalmente, foi 
de 300 s (5 min), atingindo até 1000 s em alguns níveis estratigráficos de interesse. Notaram claramente a distinção de arenitos marinhos e calcários de rochas continentais. As unidades de canais fluviais e planícies de inundação registraram altas contagens, constatando que nas últimas os valores são mais elevados. Comparativamente aos depósitos eólicos, as camadas fluviais mostraram maiores concentrações de K, eU e eTh. Tais concentrações nas planícies fluviais de inundação foram explicadas pela maior presença de feldspatos alcalinos, e dos seus produtos de graus variados de alteração para sericita, em adição as micas, cujo incremento justifica a retenção de Th, uma vez que nelas as razões $T h / K$ são maiores que nos feldspatos potássicos (ortoclásios). Concluíram que a razão eTh/K não pode ser usada para discriminar as litofácies, em função de mesclagem dos estratos eólicos e fluviais. Do mesmo modo, a razão eTh/eU se mostrou independente das litofácies, pelo que recomendaram cautela no uso deste parâmetro para interpretar ambientes deposicionais.

Forst et al. (2000) apresentaram um esquema de correlação estratigráfica de alta resolução de afloramentos do Mioceno Inferior da Formação Lagos-Portimão (Algarve, Portugal). Definiram quatro marcadores com base nas litologias, biofácies, registros de raios gama e datações isotópicas de Sr. As medidas da contagem total (CT em cps) foram espaçadas de $14 \mathrm{~cm}$, equivalentes ao diâmetro do sensor, em quatro exposições representativas das camadas siliciclásticas e carbonáticas da Formação LagosPortimão. Brachert et al. (2003) retomaram os estudos estratigráficos e bioestratigráficos da Formação Lagos-Portimão, com 0 apoio de medidas de raios gama separadas de $10 \mathrm{~cm}$, nas mesmas falésias do litoral meridional de Portugal, as quais exibem entre 30 e $80 \mathrm{~m}$ de altura e se estendem por cerca de $50 \mathrm{~km}$. Discutiram a fonte dos sedimentos clásticos, o clima, a topografia, além de analisarem as fácies e a alta frequência de ciclicidade da sedimentação.

Hadley et al. (2000) procederam um estudo gamaespectrométrico inovador, em correspondência a dados geológicos e análises de difração e fluorescência de raios- $X$, para correlacionar litologias semelhantes e afossiliferas de formações metassedimentares neoproterozóicas em área estruturalmente complexa do Noroeste da Irlanda. Após constatarem atenuação de cerca de $30 \%$ das radiações gama em solos (espessuras de até $10 \mathrm{~cm}$ ) derivados das rochas pelíticas, as medidas foram efetuadas em perfis verticais e afloramentos de rocha fresca com tempos de integração de $10 \mathrm{~s}$ (5 leituras) e $30 \mathrm{~s}$ (3 leituras), cujas médias de $\mathrm{K}$, eU e eTh foram comparadas aquelas da CT em cada ponto, além de relacionar os conjuntos de $\mathrm{K}+\mathrm{eU}+\mathrm{eTh}$ e $\mathrm{U}+$ eTh com as razões eTh/K e eTh/eU, respectivamente. Entretanto, antes de realizar as leituras de rotina, espaçadas de 50 e $100 \mathrm{~cm}$ em cerca de $1.500 \mathrm{~m}$ de perfis, procederam pelo menos 30 registros em cada ponto representativo das unidades estratigráficas e constataram variações de 10\% para o K e 0 eTh e de 20\% para 0 eU. Portanto, sugeriram que as razões eTh/K e eTh/eU podem ser mais realistas para caracterizar geofisicamente certos estratos de interesse, em função dos mencionados erros. Para assegurar a interpretação dos resultados, efetuaram leituras em área-teste de uma sucessão de quartzitos e rochas semipelíticas, as quais indicaram claramente maiores contagens nas últimas. As análises de difração (XRD) e fluorescência (XRF) de raios-X foram realizadas para identificar os minerais que hospedam os radionuclídeos (K, U e Th). Os resultados (XRD) mostraram que em uma das formações predominam quantidades elevadas e baixas de muscovita e clorita, respectivamente. As concentrações de K (XRF) guardaram boa correspondência aos dados gamaespectrométricos em ambas as formações. Concluíram que o modelo tectônico depende do controle estratigráfico e que este pode ser diferenciado pelos dados gamaespectrométricos (presença de muscovita e matéria orgânica) em uma das formações, mesmo considerando a similaridade litológica.

Lüning et al. (2000a) promoveram ampla revisão sobre a distribuição regional e os modelos deposicionais dos "hot shales" (COT > 17\%) do Siluriano Inferior do Norte da África e da Arábia. Em geral, são caracterizados por um nível basal rico em matéria orgânica e constituem as rochas geradoras de cerca de 80-90\% dos hidrocarbonetos da região. Folhelhos basais do Siluriano ocorrem também em outras bacias intracratônicas nos Estados Unidos, Brasil (Amazonas) e Rússia e são responsáveis por cerca de $9 \%$ das reservas mundiais de petróleo. No Norte da África os folhelhos negros ricos em matéria orgânica foram formados num curto período de tempo (1-2 Ma), através da conjunção de vários fatores que permitiu o desenvolvimento de um ambiente redutor excepcional. Os autores mapearam as rochas geradoras de hidrocarbonetos com base em dados de logs (raios gama, resistividade e sônico) de mais de 300 poços de exploração de petróleo na Líbia, Tunísia, Argélia e Marrocos. 0 incremento das intensidades dos raios gama guardou relação direta aos teores de COT, onde 0 urânio não detrítico (autigênico) está vinculado à matéria orgânica. Em folhelhos marinhos, $\mathrm{K}$ e Th estão presentes principalmente na forma detrítica nos minerais de argila. $0 \mathrm{U}$ detrítico também ocorre nas argilas, mas, diferentemente do Th, pode ser parcialmente lixiviado em soluções de complexos de uranil $\left(\mathrm{UO}_{2}\right)^{2+}$. Em ambientes redutores, frequentemente, é precipitado na forma autigênica em presença de matéria orgânica ou fosfatos (elevada CTC), na interface sedimento-água. Para 
Lüning et al. (2000a), os folhelhos são definidos como "hot" se as intensidades dos raios gama superam $200 \mathrm{API}$ (aproximadamente $3 \%$ de COT). A assinatura típica dos folhelhos negros ricos em matéria orgânica nos logs de poços é dada por incrementos dos raios gama e da resistividade (não são condutivos) e decréscimo nos perfis sônicos em função da baixa densidade da matéria orgânica. A matéria orgânica contida nos folhelhos altamente maturos é reduzida em função da geração e migração de hidrocarbonetos, enquanto o urânio é pouco afetado por este processo. Devido às baixas velocidades sônicas, os folhelhos negros constituem excelente refletor na prospecção sísmica. Após discutirem o tipo de matéria orgânica, a bioestratigrafia e 0 modelo deposicional/paleoecológico em vários países, concluíram que a distribuição (lateralmente descontínua) e as espessuras dos "hot shales" foram controladas pelo paleorelevo do Siluriano Inferior, o qual, por sua vez, estaria relacionado aos processos glaciais do Ordoviciano Superior e ao tectonismo compressional e extensional do evento Pan-Africano, para sugerirem que o modelo proposto pode auxiliar a prospecção de petróleo em regiões ainda pouco exploradas do Norte da África e da Arábia.

Lüning et al. (2000b), para tentar explicar os mecanismos deposicionais de horizontes ricos em matéria orgânica (máximo de 10,5\% de carbono orgânico total - COT) de folhelhos negros do Marrocos (África), coletaram e analisaram amostras oriundas de afloramentos, poços rasos para abastecimento de água e de exploração de petróleo, além de rejeitos. Os folhelhos negros do Marrocos encerram um número maior de níveis de matéria orgânica do que os equivalentes do Siluriano Inferior do Norte da África e da Península Arábica. Entretanto, verificaram que nem todos os folhelhos negros são ricos em matéria orgânica, uma vez que a cor escura, em muitos deles, é devida a presença de sulfetos microcristalinos de ferro e outros minerais como óxidos de manganês, indicativos de ambientes anóxicos e sub-anóxicos, respectivamente, ressaltando a importância da gamaespectrometria (retenção do urânio) no rastreamento subsuperficial de folheIhos negros com teores elevados de matéria orgânica (2,5 a 5\% de COT).

Lüning \& Kolonic (2003) complementaram o estudo anterior e discutiram as vantagens e limitações da gamaespectrometria, com ênfase na correlação U/COT, como ferramenta para caracterizar estratos ricos em matéria orgânica nos folhelhos negros de várias partes do mundo, em superfície e subsuperfície. Comentaram que a relação U/COT é muito variável nos folhelhos negros de diferentes idades e regiões. Referiram que as concentrações de urânio autigênico $\left(U_{\text {aut }}\right)$, em ambientes redutores, são muito maiores que seu equivalente detrítico $\left(\mathrm{U}_{\text {det }}\right)$. Sobretudo em su- cessões de folhelhos com concentrações variáveis de carbonatos, os teores de $U_{\text {aut }}$ podem ser estimados pela expressão $U_{\text {aut }}$ $=U_{\text {total }}-\mathrm{Th} / 3$, onde Th/3 se aproxima de $U_{\text {det. }}$ Nos afloramentos, as medidas foram realizadas com tempo de integração de 3 minutos e espaçadas de $10 \mathrm{~cm}$, normalmente acompanhadas de análises geoquímicas de carbono (orgânico e inorgânico), COT (após supressão do carbono inorgânico), ICP-AES (Inductively Coupled Plasma-Atomic Emission Spectrometry) e ICP-MS (Inductively Coupled Plasma-Mass Spectrometry). Com base nestes dados, em adição aos da literatura, definiram três grupos de correlação U/COT: (i) alta (e.g. Siluriano Inferior do Norte da África e da Arábia, em geral 200 API para 3\% de COT; Devoniano Superior da Argélia, U/COT = 3 ppm/\%; Devoniano Superior da América do Norte, U/COT = 5 ppm/\%; Carbonífero Superior da Inglaterra, U/COT = 3 ppm/\%; margem atlântica Leste, $\mathrm{U} / \mathrm{COT}=0,8 \mathrm{ppm} / \%$, apesar dos teores de COT superarem 15\% em ocorrências offshore do Oeste Africano; sedimentos ricos em matéria orgânica do Neógeno e do Quaternário do Leste do Mediterrâneo, U/COT = 1,3 ppm/\%); (ii) média a alta (e.g. Jurássico Inferior do Oeste da Europa, U/COT = 0,4-0,6 ou $\approx 1 \mathrm{ppm} / \%$; Evento Oceânico Anóxico do Cenomaniano-Turoniano, U/COT extremamente variável de 1,4 a 10 ppm/\%, com COT entre 10 e $35 \%$ ) e (iii) baixa (e.g. Ordoviciano da Bacia de Welsh, 6 ppm de U sem relação com COT; Devoniano da Alemanha e da Austrália, COT entre 0,4-1,0\% para 1-2 ppm de U; Cretáceo da Jordânia e Tunísia, menor que 5 ppm de U para 6\% de COT, e da Alemanha, 1,5 ppm de U para 2\% de COT; depósitos lacustrinos do Cretáceo Inferior do Gabão e do Oligoceno da Indonésia, apesar de ricos em matéria orgânica (3-4 ppm de U) não revelaram correspondência sistemática a incrementos de radioatividade). Discutiram os resultados anteriores com base em vários fatores (concentração primária de U e matéria orgânica, litologia (predominância de foIhelhos ou carbonatos), disponibilidade, capacidade de absorção de U pela matéria orgânica ou pelos fosfatos e os tipos de matéria orgânica, taxa de sedimentação e duração das condições de anoxia, grau de maturação térmica, dentre outros) e ressaltaram a necessidade de calibração em afloramentos, uma vez que nem sempre a relação U/COT é estável em todos os folhelhos negros. Finalmente enfatizaram a importância da gamaespectrometria e da razão U/COT nos estudos de correlação superfície/subsuperfície, por considerarem as dificuldades do emprego dos perfis de densidade, sônico e de resistividade em afloramentos. Vale ressaltar que Schmoker (1981) já havia proposto um método para quantificar a matéria orgânica com base em perfis de raios gama, testado em folhelhos negros devonianos dos Apalaches (USA) e apoiado em 12 análises de COT de testemunhos de poços sepa- 
rados por grandes distâncias. Para tanto propuseram a expressão $\Phi_{o}=\left(Y_{B}-Y\right) / 1.378 A$, onde $\Phi_{o}$ é 0 teor de matéria orgânica (fração de volume), $Y$ éa intensidade dos raios gama em unidades API, $Y_{B}$ é a intensidade dos raios gama (unidades API) na ausência de matéria orgânica (background) e $A$ é a inclinação da reta que relaciona os raios gama e a densidade $\left(\mathrm{g} / \mathrm{cm}^{3}\right)$. A correlação é inversa, uma vez que o incremento dos raios gama é acompanhado por decréscimo da densidade.

Lüning et al. (2004) tentaram reconstruir a distribuição espacial e temporal dos folhelhos negros do Devoniano Superior do Noroeste da África, igualmente ricos em matéria orgânica, baseados em novos dados gamaespectrométricos, bioestratigráficos e de COT oriundos de afloramentos da Bacia de Ahnet (Argélia). Inicialmente foram feitos testes (10 leituras) com vários tempos de integração (1, 2 e 3 minutos), em horizonte de radioatividade normal, os quais revelaram que os desvios-padrão decaem abruptamente do primeiro ao último, pelo que foi selecionado o tempo de 3 minutos para as leituras de rotina (separadas de 1-2 m). Os dados espectrais, na maioria das seções, revelaram um enriquecimento de urânio (12 a 32 ppm) em intervalo superior a 45 m de espessura, cujos cut-offs de 8 e 10 ppm foram utilizados como marcadores para correlacionar os perfis. As anomalias de $\mathrm{U}$, correspondentes a elevados teores de COT nos folhelhos do Frasniano Inferior, são bem conhecidas como guia na exploração de hidrocarbonetos na Argélia, Sul da Tunísia e Oeste da Líbia, cujas relações já foram comentadas. Em três das cinco seções geoquimicamente estudadas, os teores de COT raramente excedem $0,5 \%$, mas correspondem a intervalos ricos em $\mathrm{U}$, fato explicado pelo intemperismo, uma vez que as concentrações de COT em subsuperfície (Argélia) são da ordem de 7\%. Pelo contrário, horizontes ricos em matéria orgânica se vinculam, muitas vezes, a baixos níveis de $\mathrm{U}, 0$ que sugere maior participação de matéria orgânica terrígena. Portanto, para os autores, três são os fatores que controlaram a retenção de U nos afloramentos: (i) teores originais de U na matéria orgânica; (ii) duração e intensidade do intemperismo e (iii) perda de carbono orgânico durante o soterramento e a maturação térmica.

Lüning et al. (2005) apresentaram um modelo deposicional e mapearam os folhelhos negros ricos em matéria orgânica na Jordânia, para discutirem suas implicações na exploração de hidrocarbonetos, com base em logs de raios gama de mais de 50 poços, determinações de COT e dados bioestratigráficos.

Svendsen \& Hartley (2001), em estudo comparativo de dados gamaespectrométricos e geoquímicos de uma sucessão fluvial da Formação Otter Sandstone (Triássico do Reino Unido), procuraram entender a distribuição dos radioelementos nas várias fases minerais para discutir suas similaridades e diferenças. A seção estudada, com $68 \mathrm{~m}$ de espessura, constituída por arenitos finos a médios depositados em ambientes fluviais e lacustres, climas áridos a semi-áridos, foi considerada um excelente reservatório análogo próximo do Wytch Farm Oilfield. As medidas de $\mathrm{K}$, eU e eTh foram adquiridas com espaçamento de $20 \mathrm{~cm}$ e tempo de integração de 2 min, selecionado após vários experimentos, permitindo uma precisão de cerca de 10\%. Para as análises geoquímicas foram coletadas 42 amostras, separadas de 1,5 m, nos mesmos pontos dos registros gamaespectrométricos. Os elementos maiores e alguns traços $(\mathrm{Ba}, \mathrm{Co}, \mathrm{Cr}$, $\mathrm{Cu}, \mathrm{Li}, \mathrm{Sc}, \mathrm{Sr}, \mathrm{Zn}$ ) foram analisados pelo método ICP-AES, enquanto os demais elementos-traço e terras raras foram determinados por ICP-MS. Mostraram que os valores da contagem total (CT) se correlacionam idealmente aos do potássio $(r=0,93)$ e em menor grau aos do urânio e do tório, respectivamente 0,82 e 0,87 . As razões dos dados espectrais também foram consideradas significativas ( $r=0,60$ para K/eU, $r=0,68$ para K/eTh e $r=0,76$ para eU/eTh). Conglomerados, arenitos e rochas argilosas da sucessão fluvial foram bem determinados, respectivamente, por baixos, intermediários e altos valores de CT, K, eU e eTh. Do ponto de vista geoquímico, verificaram que o $Z n$ se vincula melhor às argilas do que aos óxidos de alumínio, na ausência de quantidades significativas de minerais ferromagnesianos e sulfatos, uma vez que $\mathrm{Al}_{2} \mathrm{O}_{3}$ predomina nos feldspatos potássicos. Revelaram por fim o potencial dos dados gamaespectrométricos na identificação mineralógica e litológica, na distribuição das argilas, metais pesados e rochas com cimento carbonático e discutiram suas implicações na caracterização quantitativa de reservatórios.

Doveton \& Merriam (2004) estudaram treze níveis de folheIhos negros pensilvanianos do Kansas (USA), com base em perfis espectrais de raios gama, nêutrons, densidade e do fator fotoelétrico de 23 poços. Apesar de pouco espessos, se estendem por grandes áreas e constituem um excelente marcador para correlações estratigráficas, como apresentado em detalhe por Filer (2002). A elevada radioatividade foi creditada ao incremento de U na matéria orgânica (10 a 15\% de COT) e nas concreções de fosfato. Cloritas, illitas e caolinitas constituem seus principais minerais de argila. Utilizaram o parâmetro $\mathrm{K}+$ eTh para calcular o volume dos folhelhos, considerado subestimado em função de elevadas concentrações de calcita. A razão eTh/K permitiu reconhecer os minerais de argila (illita e esmectita são ricas em $\mathrm{K}$, em contraste a caulinita e a clorita) e distinguir as micas dos feldspatos potássicos. Notaram também que 0 enriquecimento ou depleção do K são proporcionais ao Th. Já a razão eTh/eU 
foi empregada como sugestiva das condições de oxi-redução. Concluíram que os perfis petrofísicos se vinculam ao quimismo dos folhelhos negros e podem ser utilizados para esboçar a quimioestratigrafia de subsuperfície.

Betzler et al. (2007) procederam leituras espectrais separadas de $15 \mathrm{~cm}$, tempo de integração de $3 \mathrm{~min}$, em exposição de $64 \mathrm{~m}$ de espessura da Formação Korallenoolith, Norte da Alemanha. Os resultados permitiram identificar seis fácies e interpretar 0 ambiente deposiconal de uma rampa carbonática, em adição a critérios composicionais, texturais e análises de difração de raiosX. A boa correlação dos dados gamaespectrométricos e de ciclicidade sedimentar verificada no afloramento foi considerada importante para o estudo de estratos análogos em subsuperfície.

Evans et al. (2007) realizaram 22 perfis de contagem total (CT em cps) em uma área $(50$ x $6500 \mathrm{~m})$ de exposição do arenito Tumblagooda (sistema flúvio-deltáico do Ordoviciano Superior da Bacia Carnarvon), no litoral Oeste da Austrália, onde foi possível mapear unidades subsísmicas e fácies sedimentares. A definição de cinco unidades estratigráficas foi baseada em medidas (cinco leituras por amostra) espaçadas de 50 e $25 \mathrm{~cm}$ e tempos de integração de 10 e $1 \mathrm{~s}$, respectivamente, sempre associadas a análises granulométricas, litológicas e estruturas sedimentares, tendo verificado que os raios gama permitiram identificar mudanças litológicas sutis de difícil reconhecimento no campo. Com base nos resultados obtidos discutiram as implicações para 0 estabelecimento de modelos de fluxo e reservatórios análogos, como os campos do Permiano do Sul da Austrália, em termos de correlação estratigráfica, granulometria, forma, dimensões e heterogeneidades internas dos corpos, mesmo considerando que nos perfis de poços a resolução seja menor que $30 \mathrm{~cm}$.

\section{Contexto geológico regional}

Considerada uma das mais proeminentes sinéclises do continente Sul-Americano, a Bacia do Paraná alcança atualmente uma área aproximada de $1.500 .000 \mathrm{~km}^{2}$, preservando mais de 7.000 metros de rochas sedimentares e magmáticas na sua porção central, com lindes em tratos situados no Centro-Sul do Brasil, Norte do Uruguai, Mesopotâmia Argentina e Oeste Paraguaio. Seu registro estratigráfico iniciou no Neo-ordoviciano $(\approx 450 \mathrm{Ma})$, com as primeiras incursões marinhas, passando por estágios de glaciação no Neo-carbonífero e desertificação do interior continental no intervalo Triássico-Jurássico, além de um importante evento magmático Mesozóico, até o final da sedimentação no Neo-cretáceo ( $\approx 65 \mathrm{Ma})$. No intervalo de aproximadamente 385 Ma de sua história evolutiva, períodos descontínuos de sedimentação foram limitados por discordâncias regionais rela- cionados a variações eustáticas do nível do mar. Tais oscilações foram vinculadas a eventos de subsidência ocorridos no continente em resposta aos esforços orogênicos paleozóicos na borda Oeste e ao processo de abertura do Oceano Atlântico Sul, a Leste (Milani, 1997). Em trabalhos de síntese, Zalán et al. $(1987,1990)$ propuseram um arcabouço estrutural e discutiram sua influência na evolução tectono-sedimentar da Bacia do Paraná.

A bacia desenvolveu-se sobre um arcabouço proterozóico de blocos cratônicos circundados por cinturões de dobramentos e empurrões com orientação predominante NE, sendo o provável mecanismo propulsor da subsidência inicial a reativação transtensional de lineamentos intraplaca sob o campo de tensões compressional relacionado à orogenia Oclóica, causada pela interação colisional do Gondwana e terrenos da Precordilheira (Milani, 1997).

Milani $(1997,2004)$ definiu seis supersequências para a Bacia do Paraná, as quais compõem seu arcabouço estratigráfico. De acordo com Milani (2004) e Milani et al. (2007), as supersequências Rio Ivaí (0-S), Paraná (D) e Gondwana I (Neo-C - E0-Tr) documentam grandes ciclos transgressivos-regressivos paleozóicos de variação do nível de base, enquanto as supersequências Gondwana II, Gondwana III e Bauru encerram sucessões sedimentares continentais mesozóicas e rochas ígneas associadas.

\section{Contexto tectono-estratigráfico da Formação Ponta Grossa}

Desde 0 trabalho pioneiro de Derby (1878 apud Petri, 1948), vários autores se dedicaram ao estudo da Formação Ponta Grossa com ênfase no conteúdo fossilifero (Clarke, 1913; Oliveira, 1927; Petri, 1948; Maack, 1950-51; Bigarella \& Salamuni, 1967; Daemon et al., 1967; Lange, 1967; Lange \& Petri, 1967).

A Formação Ponta Grossa, depositada em ambiente marinho raso (plataformal), comprovado pela profusão de fósseis (e.g. Daemon et al., 1967; Lange, 1967), é uma unidade dominantemente pelítica com intercalações esporádicas de lentes arenosas. A seção de superfície mais representativa é aquela da estrada entre as cidades de Tibagi e Telêmaco Borba, Estado do Paraná, na qual podem ser visualizados 250 metros de seus litotipos (membros Jaguariaíva, Tibagi e São Domingos, Fig. 1). Em subsuperfície 0 registro de maior espessura é o do poço Apucarana (2-AP-I-PR), onde a unidade alcança 654 metros (Fig. 2).

A Supersequência Paraná (Milani, 2004; Milani et al., 2007) é formada por duas unidades principais: formações Furnas e Ponta Grossa (Fig. 1). A primeira iniciou sua deposição no E0devoniano (Lochkoviano, $\approx 410 \mathrm{Ma}$, Fig. 1) e culminou no Neodevoniano (Emsiano, $\approx 390 \mathrm{Ma}$, Fig. 1), enquanto a segunda se 


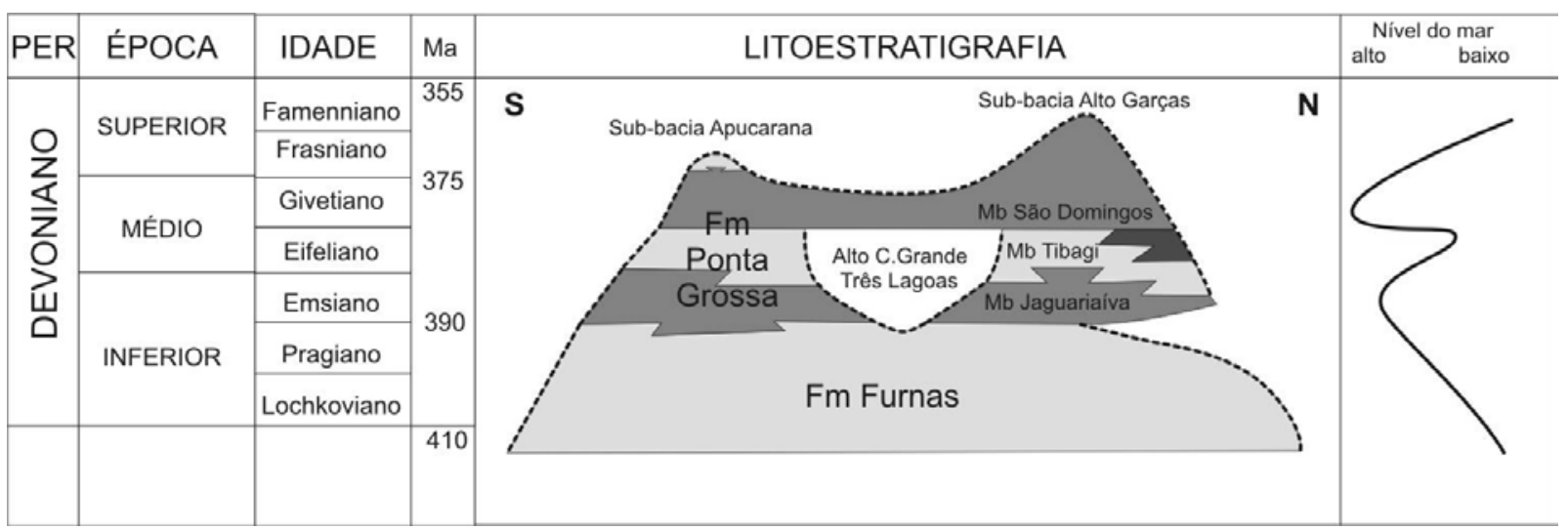

Figura 1 - Carta cronoestratigráfica das formações Furnas e Ponta Grossa indicando o Alto Três Lagoas-Campo Grande, as sub-bacias Apucarana e Alto Garças e os membros da Formação Ponta Grossa (Assine et al., 1998).

sedimentou entre 390-360 Ma (Emsiano-Frasniano/Famenniano, Fig. 1), período no qual a Bacia do Paraná experimentou uma das mais importantes inundações marinhas, bem documentada pelos folhelhos fossilíferos dos membros Jaguariaíva (base) e São Domingos (topo). Tais folhelhos, predominantes na Formação Ponta Grossa, com teores de matéria orgânica de até 2\% (Bergamaschi, 1999), são considerados geradores de hidrocarbonetos para o Sistema Petrolífero Ponta Grossa-Itararé. Entretanto, seu potencial como intervalo portador de arenitos-reservatório normalmente é negligenciado, em contraste aos níveis estratigráficos permo-carboníferos (Candido, 2007).

Em subsuperfície, a área de estudo compreende toda a extensão da Formação Ponta Grossa no Brasil, envolvendo os estados de Santa Catarina, Paraná, São Paulo, Mato Grosso do Sul, Mato Grosso e Goiás. Os perfis litológicos e geofísicos utilizados na pesquisa, disponíveis na UFPR, são oriundos de poços perfurados pela Petrobras e Paulipetro que atravessaram a Formação Ponta Grossa (Fig. 2).

Mais recentemente, Assine et al. (1994) e Assine \& Petri (1996) contribuíram para o conhecimento da Formação Ponta Grossa, principalmente em termos de ambientes de sedimentação. Assine (1996) e Assine et al. (1998) abordaram a temática no contexto da Estratigrafia de Sequências, seguido por Pereira \& Bergamaschi (1996), Bergamaschi (1999), Pereira (2000), Candido (2007) e Candido \& Rostirolla (2007).

Ramos (1970) foi o primeiro autor a sugerir que o Alto Três Lagoas-Campo Grande separou a Formação Ponta Grossa em duas sub-bacias: Apucarana ao Sul e Alto Garças ao Norte (Fig. 1). Ferreira et al. (1981), a partir da interpretação de dados aeromagnéticos e do mapa de isópacas da Formação Ponta Grossa de Northfleet et al. (1969), consideraram o Alinhamento de Guapiara, limite setentrional do Arco de Ponta Grossa (APG), como uma feição tectônica soerguida que separou as referidas sub-bacias (Fig. 2), ao discutirem a atuação conjunta, no Devoniano, dos arcos de Campo Grande e Ponta Grossa. Em adição a este quadro, Zalán et al. $(1987,1990)$ definiram 0 Lineamento de Araçatuba (Fig. 2), de direção NE, cujo cruzamento com o Alinhamento de Guapiara coincide com o Alto Estrutural de Três Lagoas.

Lange (1967), com base no conteúdo fossilífero, sugeriu que 0 APG atuou como um baixo estrutural no Devoniano. Ferreira (1982a,b) admitiu que a sub-bacia Apucarana preservou as maiores espessuras da Formação Ponta Grossa na região limitada pelos alinhamentos de São Jerônimo-Curiúva e do Rio Alonzo (domínio central do APG, Fig. 2).

0 Alinhamento do Rio Piquiri (limite meridional do APG, Fig. 2), foi considerado por Ferreira (1982a,b) como feição tectônica positiva responsável pela demarcação Sudoeste da sub-bacia Apucarana. Com a continuidade para 0 interior da bacia da Falha de Jacutinga (Fig. 2), proposta por Zalán et al. $(1987,1990)$, é possível que a sub-bacia Apucarana tenha sido limitada pelo cruzamento dos lineamentos de Guapiara e do Rio Piquiri segundo NW, com os de Araçatuba e Jacutinga segundo NE (Fig. 2).

Ferreira (1982a,b) e Fúlfaro et al. (1982) relataram a influência das estruturas NW, principalmente vinculadas ao APG, na compartimentação da Formação Ponta Grossa e na evolução tectônica da Bacia do Paraná.

Em superfície, é perceptível o espessamento da Formação Ponta Grossa em direção ao eixo do arco homônimo (Fig. 3), atingindo aproximadamente 250 metros nas proximidades de Tibagi. Já a Nordeste de Arapoti e a Sudeste de Ponta Grossa, em correspondência, respectivamente, aos alinhamentos de São Jerônimo-Curiúva e do Rio Alonzo, tal formação apresenta-se delgada, aflorando praticamente o Membro Jaguariaíva (basal). 


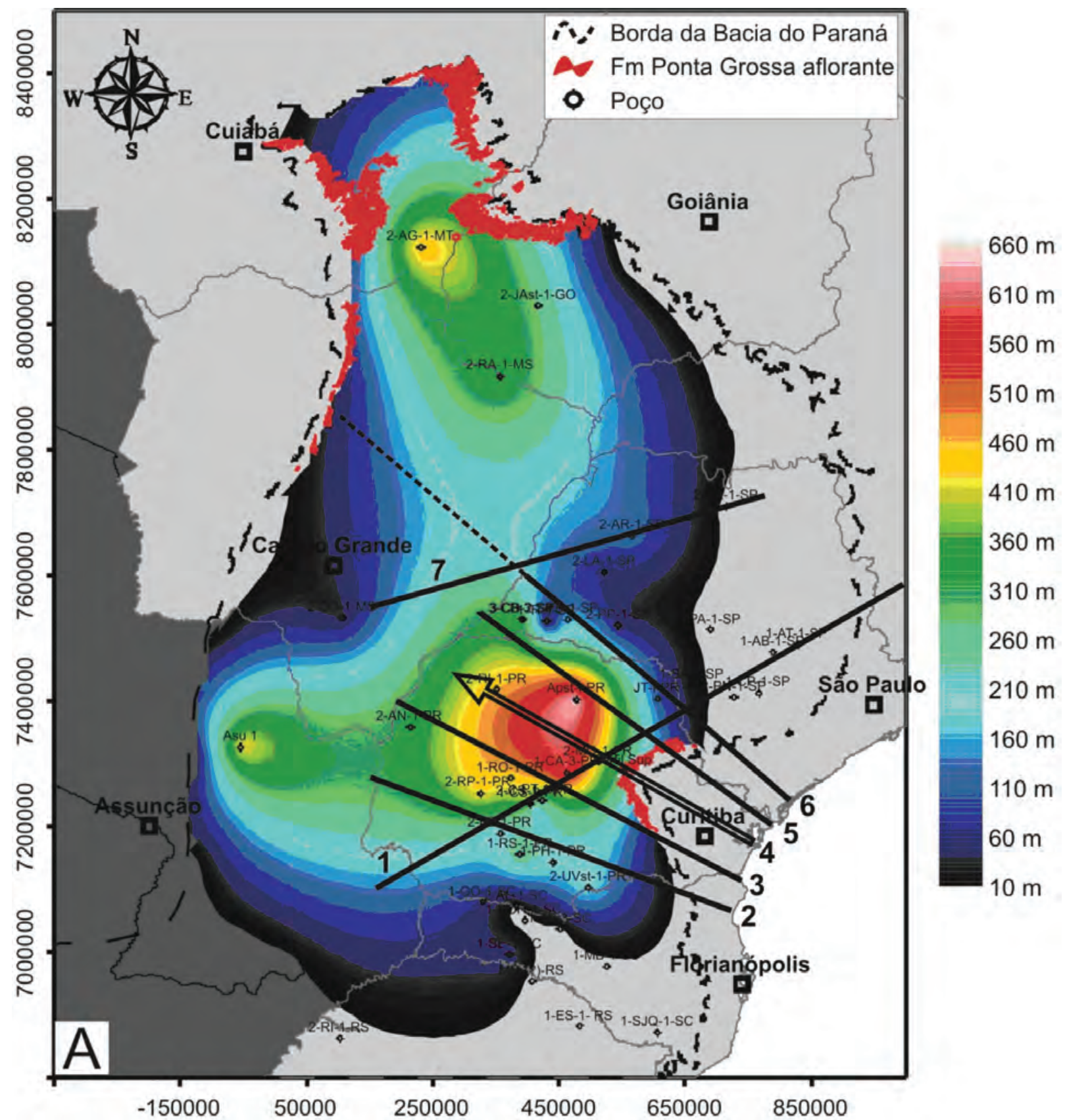

Figura 2 - Mapa de isópacas da Formação Ponta Grossa (modificado de Candido, 2007) indicando as principais estruturas (Ferreira 1982a,b; Zalán et al., 1987, 1990). 1 - Falha de Jacutinga; 2 - Alinhamento do Rio Piquiri; 3 - Alinhamento do Rio Alonzo; 4 - Eixo do Arco de Ponta Grossa; 5 - Alinhamento de São JerônimoCuriúva; 6 - Alinhamento de Guapiara; 7 - Lineamento de Araçatuba.

\section{LOCALIZAÇÃO DOS PERFIS GAMAESPECTROMÉTRICOS}

Os levantamentos gamaespectrométricos foram realizados em quatro seções da Formação Ponta Grossa no Estado do Paraná, distribuídas pelos municípios de Arapoti, Jaguariaíva, Tibagi e Ponta Grossa (Fig. 4).
0 perfil Arapoti (Fig. 4), 30 metros de espessura, foi realizado na perspectiva de identificar variações sutis nos teores de argila das denominadas Camadas de Transição (Petri, 1948), posicionadas na interface das formações Furnas e Ponta Grossa, enquanto o perfil Jaguariaíva (Fig. 4), 12 metros de espessura, foi executado preferencialmente com o intuito de averiguar a pratici- 


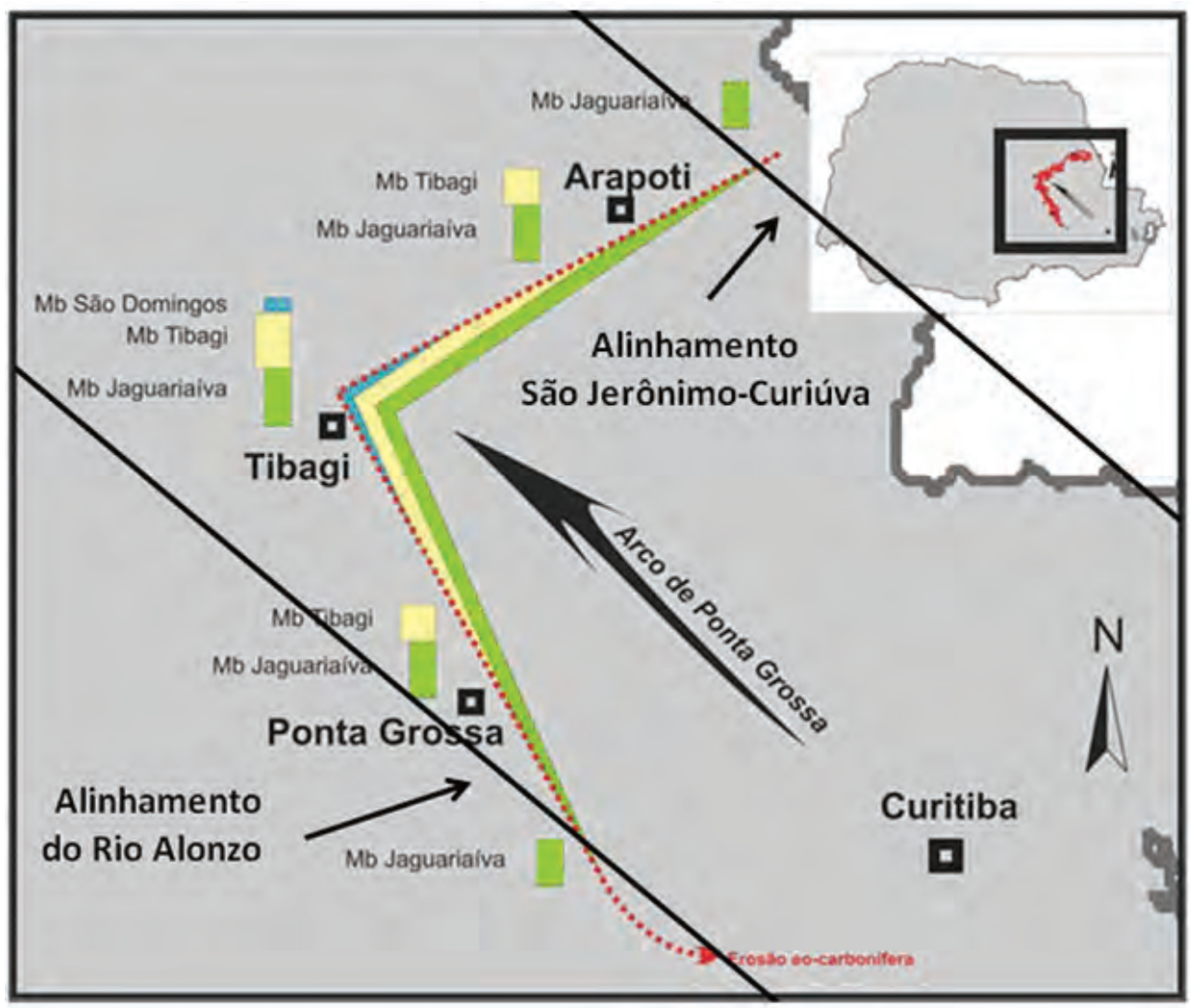

Figura 3 - Mapa esquemático da distribuição dos afloramentos e das espessuras dos membros da Formação Ponta Grossa indicando os alinhamentos de São Jerônimo-Curiúva e do Rio Alonzo (domínio central do Arco de Ponta Grossa segundo Ferreira, 1982a,b).

dade e as respostas do método gamaespectrométrico. Os perfis Arapoti e Jaguariaíva estão situados na rodovia PR-092, entre os municípios homônimos (Fig. 4).

0 perfil Tibagi (Fig. 4), 250 metros de espessura, posicionado no intermédio dos municípios de Telêmaco Borba e Tibagi, na rodovia PR-340, foi considerado o mais importante, pois sua localização na região central do Arco de Ponta Grossa permitiu boas exposições da formação homônima, representadas pelos seus membros Jaguariaíva, Tibagi e São Domingos. Além disso, a estrada na qual a seção foi levantada dispensou correções de espessura das camadas, uma vez que se dispõe perpendicularmente à faixa de afloramentos da formação .

0 perfil Ponta Grossa (Fig. 4), 16 metros de espessura, situado na margem direita do rio Tibagi, na estrada que liga 0 bairro Santa Paula ao município de Teixeira Soares, foi realizado em um único corpo que grada de folhelhos para arenitos, onde ocorrem boas exposições de estruturas sedimentares a partir das quais também foram feitas interpretações sobre a analogia poço/superfície.

\section{MATERIAL E MÉTODOS}

\section{Gamaespectrometria de superfície}

Os dados gamaespectrométricos de superfície $(50 \mathrm{~cm}$ nos arenitos e $100 \mathrm{~cm}$ nos folhelhos) foram coletados simultaneamente à elaboração e descrição dos perfis litoestratigráficos, onde as medidas de espessura das camadas foram feitas com visadas em bússolas com clinômetro.

Foram utilizados dois gamaespectrômetros pertencentes ao Laboratório de Pesquisas em Geofísica Aplicada (LPGA/UFPR): GRS-500 e GS-512. 0 modelo GRS-500 (Differencial Gamma Ray Spectrometer/Scintilometer, fabricação Scintrex, Canadá) encerra a sonda e o sistema de medição num único módulo (23,5 $\times 64,0 \times 11,5 \mathrm{~cm}$, pesa $4,5 \mathrm{~kg}$ ) e opera em intervalo de $0,08 \mathrm{a}$ $0,70 \mathrm{MeV}$ com uma fonte radioativa $\left({ }^{137} \mathrm{Cs}\right)$ de referência e outra de calibração $\left.{ }^{133} \mathrm{Ba}\right)$, cujo fotopico é de 0,352 MeV. Possui duas janelas de contagem total (TC $1>0,08 \mathrm{MeV}$ e TC $2>$ 0,40 MeV), além dos seguintes intervalos energéticos, respectivamente do potássio (K) e dos equivalentes de urânio (eU) e 


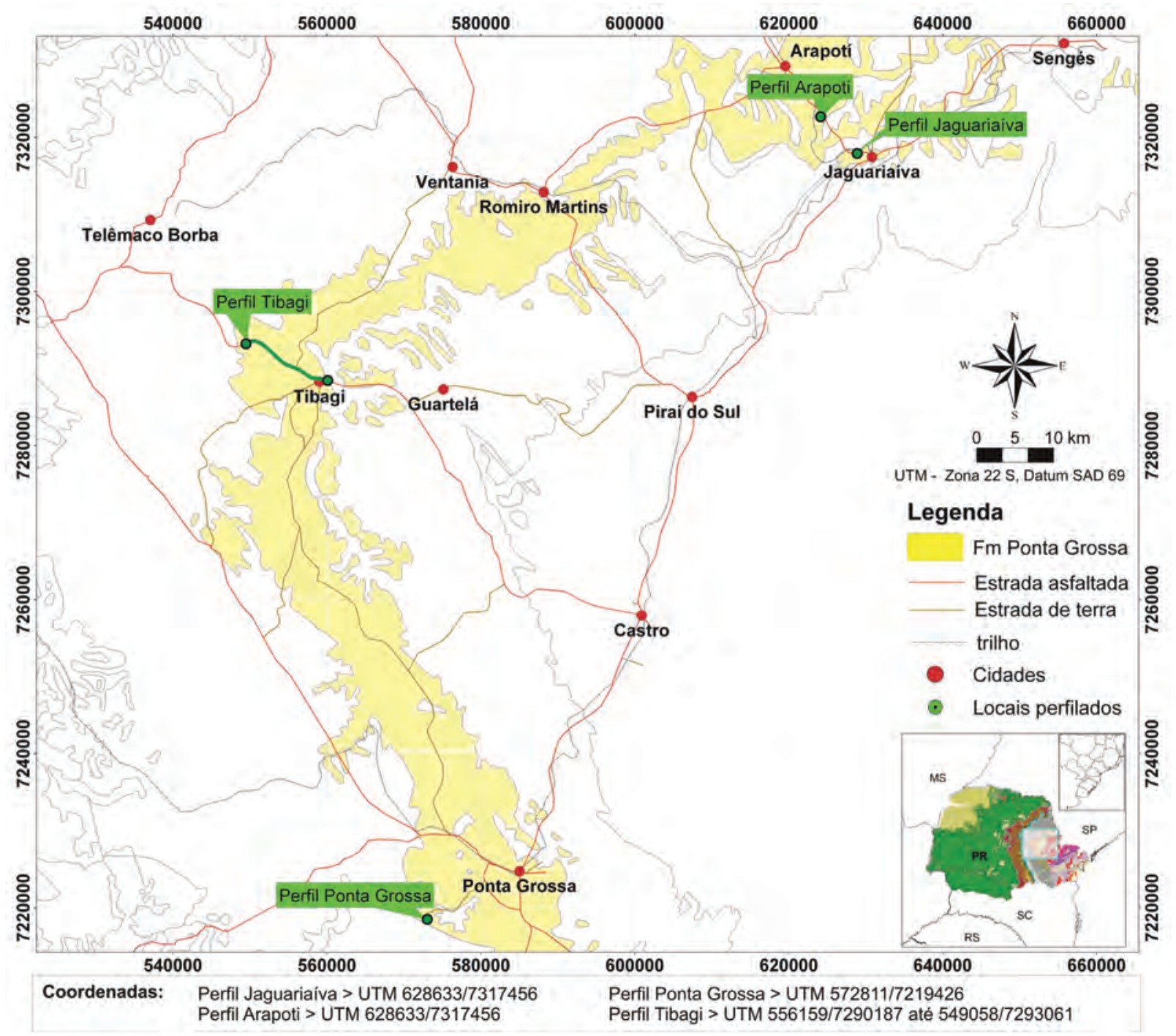

Figura 4 - Mapa de localização dos perfis gamaespectrométricos Arapoti, Jaguariaíva, Tibagi e Ponta Grossa.

tório (eTh): 1,35 a 1,59 MeV, 1,65 a 1,87 MeV e 2,45 a 2,79 MeV. 0 GRS-500 pode operar com dois tempos de integração: um e dez segundos, este último utilizado nas medições em todas as janelas referidas. As primeiras aferições de campo realizadas com 0 GRS-500 foram consideradas satisfatórias, a partir das quais se notou a viabilidade do método. Entretanto, como o instrumento é analógico (não possui memória para gravar as leituras), os registros são adquiridos (e anotados), separadamente, para os canais TC1, TC2, K, eU e eTh, do que decorre um tempo de leitura extremamente elevado, podendo superar 5 minutos por ponto.

0 modelo GS-512 (Gamma Ray Spectrometer, fabricação Geofyzika, República Tcheca), foi projetado para operar com 512 canais num intervalo de 0,1 a 3,0 MeV. A radiação cósmica, superior a 3,0 MeV, foi automaticamente monitorada pelo GS-512. 0 instrumento consiste de uma sonda ( $45 \mathrm{~cm}$ de comprimento, $12,5 \mathrm{~cm}$ de diâmetro e pesa 4,6 kg), a qual encerra um cristal $(76 \times 76 \mathrm{~mm})$ de $\mathrm{Nal}(\mathrm{TI})$, além de um circuito de detecção e uma fonte radioativa $\left({ }^{137} \mathrm{Cs}\right)$ de referência. Outro módulo $(23,5 \times 23,0$ $\times 9,0 \mathrm{~cm}$ ) armazena (mais de 8.500 leituras) e processa os dados medidos, os quais podem ser transferidos para um computador através de um cabo RS-232. 0 GS-512 foi calibrado (veja procedimentos em Becegato \& Ferreira, 2005) no Instituto de Radioproteção e Dosimetria (IRD) da Comissão Nacional de Energia Nuclear (CNEN), permitindo leituras da contagem total (CT), em ppm de urânio equivalente (Ueq), potássio (K) em \%, equi- 
valentes de urânio (eU) e equivalentes de tório (eTh) em ppm. Além das vantagens mencionadas, o GS-512 possui tempo de integração variável (máximo de 24 horas).

No caso do perfil Tibagi, por exemplo, ao longo dos $250 \mathrm{~m}$ de exposição da Formação Ponta Grossa, com o modelo GS-512, foram feitas medidas espaçadas de $50 \mathrm{~cm}$ nos arenitos e $100 \mathrm{~cm}$ nos folhelhos, envolvendo aproximadamente 310 leituras, com tempo de integração de 120 segundos, consumindo 620 minutos, portanto menos da metade do tempo requerido pelo GRS-500 para realizar a mesma tarefa.

0 processamento foi feito através de planilha Excel, na qual todos os dados adquiridos, em cps e concentrações, foram tabulados e posteriormente representados em gráficos de forma similar aos logs de poços profundos, onde picos de maior ou menor radioatividade representariam níveis argilosos e arenosos, respectivamente.

\section{Gamaespectrometria de poço}

Os poços encerram dados relevantes para o estudo de subsuperfície, pois permitem visualizar espacialmente uma determinada unidade da bacia, uma vez que fornecem informações sobre 0 empilhamento litológico, granulométrico e estratigráfico. Em especial no caso da Formação Ponta Grossa (unidade muito profunda e raramente perfurada por completo), os perfis geofísicos de poços são de grande valia, considerando a escassez de afloramentos em adição a sua má conservação decorrente do elevado grau de alteração intempérica.

Originalmente os perfis de poços foram disponibilizados para a pesquisa na forma analógica, os quais continham rasuras e imperfeições que dificultaram as interpretações. Assim sendo, foi necessário uma avaliação crítica seguida de digitalização e vetorização dos perfis. Tais processos permitiram editar topo e base de unidades, refinar segmentos originalmente ilegíveis, medir as espessuras de intervalos, remover as soleiras de diabásio, dentre outras atividades.

No interior da Bacia do Paraná a Formação Serra Geral (Cretáceo Inferior) é constituída preferencialmente por soleiras de diabásio, as quais estão intrudidas em intervalos argilosos. A Formação Ponta Grossa constitui sítio preferencial para hospedar tais rochas (soleiras com mais de 600 metros de espessura são registradas), uma vez que é formada em sua maioria por folheIhos. Como as soleiras não integram a sequência deposicional original da unidade, foi conveniente removê-las para facilitar a visualização, a correlação e a interpretação conjunta dos perfis dos poços.

Considerando que os dados de radiação gama dos poços estudados foram apenas adquiridos no canal da contagem total (CT) e expressos por contagens por segundo (cps) em unidades API (unidade empírica de radiação gama utilizada em perfis radioativos de poços pelo American Petroleum Institute - API/USA, Sheriff, 1999; Duarte, 2003), a correlação aos dados de superfície foi feita apenas para o referido canal (ppm de Ueq para os dados de superfície e unidades API para os dados de subsuperfície). A definição de 200 unidades API está relacionada a uma formação (folhelho), artificialmente radioativa, construída pela Universidade de Houston (Texas), a qual contém aproximadamente 4\% de K, 24 ppm de The 12 ppm de U (Ellis \& Singer, 2008). Ultimamente, os detectores de raios gama dos poços são espectrais, uma vez que registram separadamente as contagens do $\mathrm{K}$, do eTh, do eU e da CT, além de serem calibrados em unidades API ( $\gamma_{\text {API }}$ $=4 \mathrm{Th}+8 \mathrm{U}+16 \mathrm{~K}$, onde The U são expressos em ppm e K em $\%$, segundo Ellis \& Singer, 2008). Embora 0 intervalo de amostragem dos perfis de radioatividade dos poços seja de $20-30 \mathrm{~cm}$, em contraste ao dos perfis gamaespectrométricos de superfície (50 cm nos arenitos e $100 \mathrm{~cm}$ nos folhelhos), os resultados qualitativos de correlação alcançados foram considerados satisfatórios, como será discutido a seguir.

\section{RESULTADOS E DISCUSSÃO}

\section{Perfil Arapoti}

Os arenitos costeiros do topo da Formação Furnas e dos foIhelhos da base da Formação Ponta Grossa, bem caracterizados em superfície e subsuperfície, foram denominados Camadas de Transição por Petri (1948), as quais suportaram a interpretação de uma passagem gradativa das referidas unidades (e.g. Lange \& Petri, 1967; Soares et al., 1978; Soares, 1992; Milani, 1997, 2004). Contudo, Bigarella \& Salamuni (1967) postularam uma discordância entre as formações Furnas e Ponta Grossa. Zalán et al. (1987) resgataram tal proposta e sugeriram um hiato de cerca de 10 Ma das citadas formações.

Dados de três afloramentos das Camadas de Transição discutidos em Candido (2007) se revelaram inconclusivos. Em um dos pontos não foi verificado nenhum indício de discordância, apesar da exposição de 25 metros das camadas de transição. Já nos outros dois se detectou um intervalo com menos de 1 metro de espessura na zona de interface, composto por arenitos de granulação fina a média exibindo intercalações argilosas centimétricas, clastos de argila dispersos nos arenitos e níveis com concreções ferruginosas, estes últimos sugestivos de uma discordância de pequena magnitude, talvez uma paraconformidade, com exposições esporádicas. Em subsuperfície a configuração é 


\section{Perfil do poço 2-TB-1-SP}

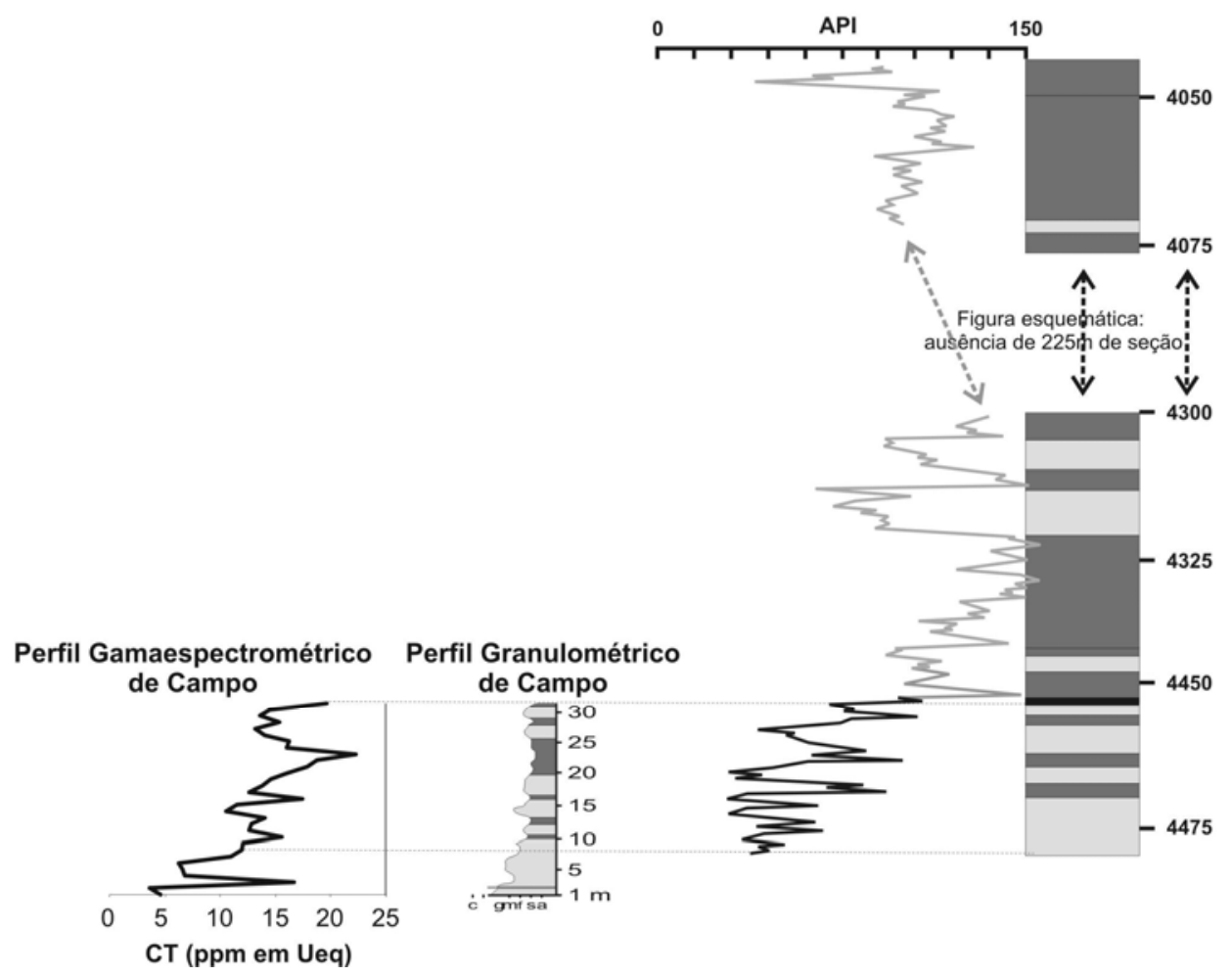

Figura 5 - Comparação de perfis gamaespectrométricos de superfície (esquerda), granulométrico (centro) e do poço 2-TB-1-SP (direita) indicando as camadas de transição.

suave, com altos e depressões pouco pronunciados. Provavelmente nos altos pode ter havido pequenas perdas de seção em decorrência de quedas sutis do nível do mar, enquanto nos baixos a sedimentação foi contínua. Talvez este seja um dos motivos segundo o qual a controvérsia sobre a existência, ou não, de uma discordância entre as formações Furnas e Ponta Grossa ainda persista na literatura (Candido, 2007).

A Figura 5 (Iocalização na Fig. 4) mostra o perfil gamaspectrométrico/granulométrico de campo, com aproximadamente 30 metros de espessura, em correspondência ao perfil do poço 2-TB1-SP, na qual as Camadas de Transição denotam clara tendência de incremento da fração argila em direção ao topo (granodecrescência ascendente), até se confundir com a base do Membro Jaguariaíva, horizonte homogêneo de folhelhos ricos em matéria orgânica com intercalações escassas e subordinadas de lâminas ou lentes de arenitos muito finos e siltitos.

\section{Perfil Jaguariaíva}

Os resultados obtidos no perfil Jaguariaíva, apesar de pouco espesso (12 metros de espessura), são significativos, uma vez que as variações litológicas são similares às dos demais perfis da Formação Ponta Grossa. Além disso, houve coerência das respostas gamaespectrométricas medidas e esperadas para cada camada e litotipo. A Figura 6 (localização na Fig. 4), mostra 0 afloramento do perfil Jaguariaíva, sobre 0 qual foram sobrepostas as curvas da contagem total obtidas pelos dois gamaespectrômetros (GS-512 e GRS-500), onde é possível notar com clareza a diminuição das intensidades nas camadas arenosas (setas vermelhas) e a queda abrupta dos valores a partir do contato dos arenitos basais do Grupo Itararé (linha vermelha tracejada).

\section{Perfil Tibagi}

Os resultados mais expressivos foram alcançados no perfil Tibagi (250 metros de espessura, localização na Fig. 4), cujos dados foram obtidos apenas com 0 gamaespectrômetro GS-512, pelas razões já comentadas. Tais resultados foram creditados à adequada calibração do instrumento e a qualidade dos afloramentos perfilados. Nesta seção foi possível observar todas as características gamaespectrométricas esperadas para 0 intervalo amostrado. 


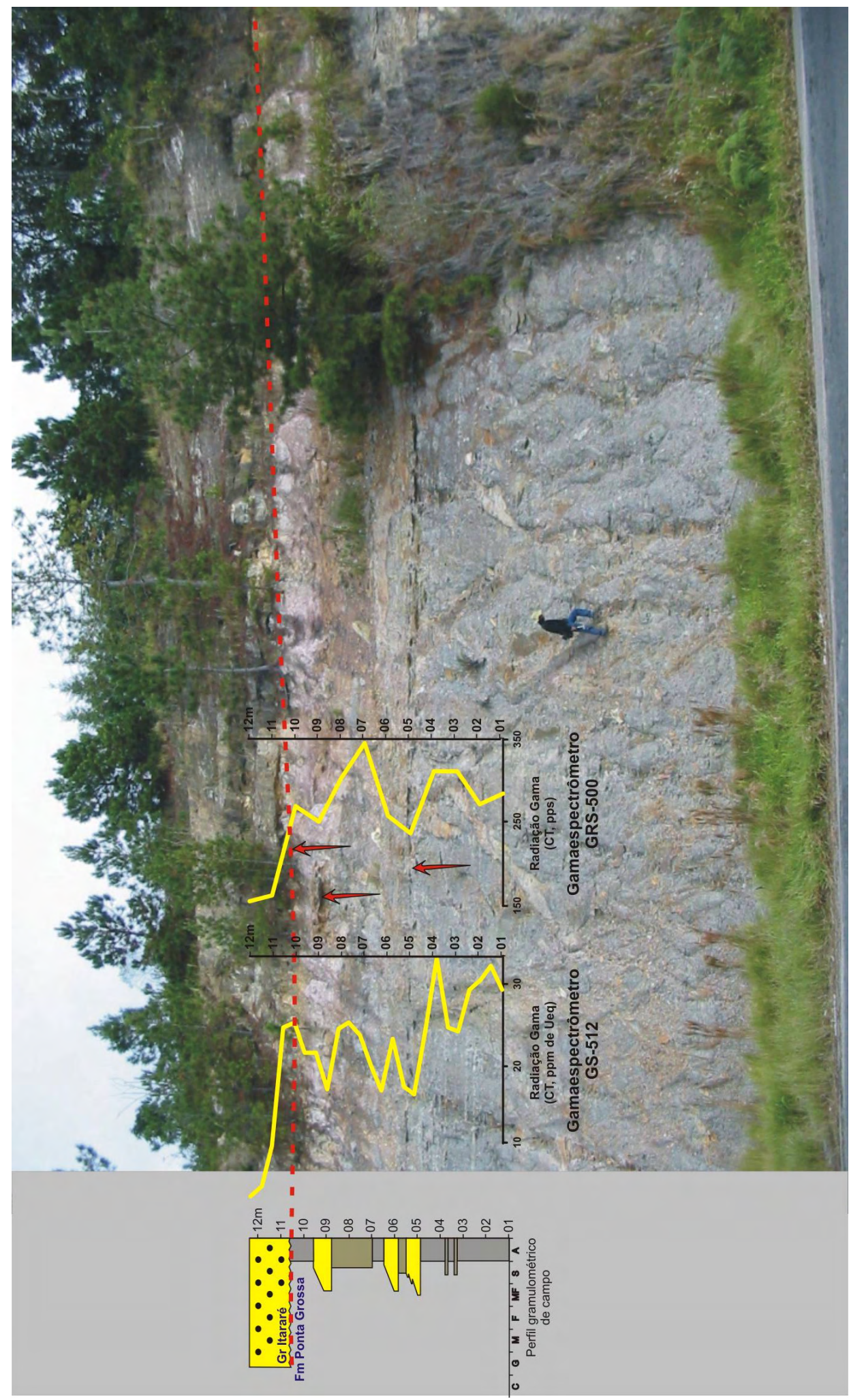

Figura 6 - Comparação das respostas dos gamaespectrômetros GS-512 e GRS-500 no perfil Jaguariaíva. Em ambas as curvas notar a diminuição das contagens nos horizontes correspondentes a camadas arenosas da Formação Ponta Grossa (setas vermeIhas), além da queda abrupta dos valores a partir do contato dos arenitos basais do Grupo Itararé (linha vermelha tracejada). 


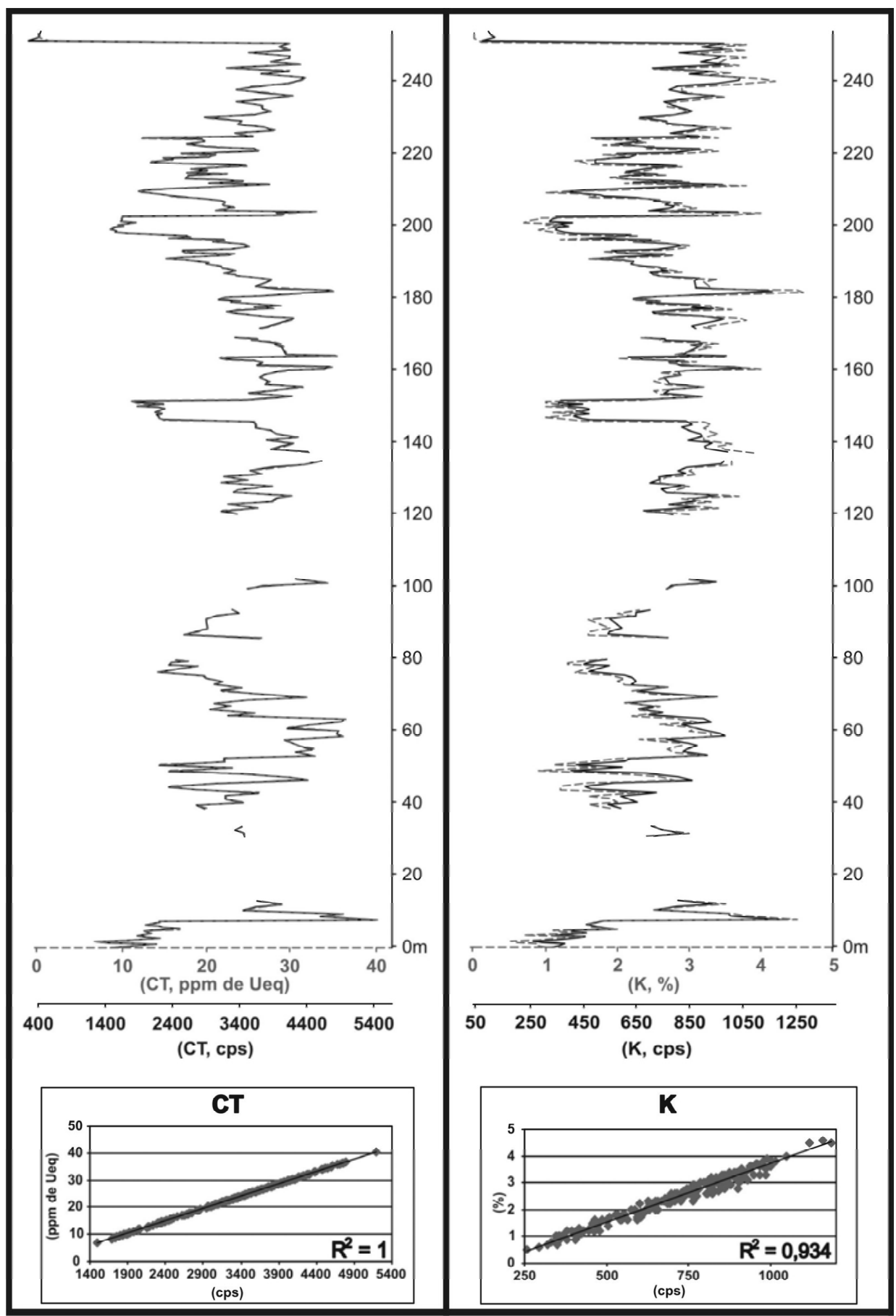

Figura 7a - Perfis gamaespectrométricos e gráficos de correlação (concentrações, linhas cheias versus cps, linhas tracejadas) dos canais CT e K na seção Tibagi.

Das quatro variáveis (CT, K, eU e eTh), a contagem total (CT), talvez pela sua larga faixa energética, revelou-se mais precisa e coerente com a análise estratigráfica pretendida. Para verificar tal constatação, foram elaborados perfis comparativos e gráficos de correlação dos dados em concentrações e contagens por segundo (cps) das variáveis mencionadas (Figs. 7a e 7b). Nota-se na Figura $7 b$ que 0 índice de correlação no canal do urânio é relativamente baixo $\left(\mathrm{R}^{2} \approx 0,75\right)$, em correspondência a uma disper- 


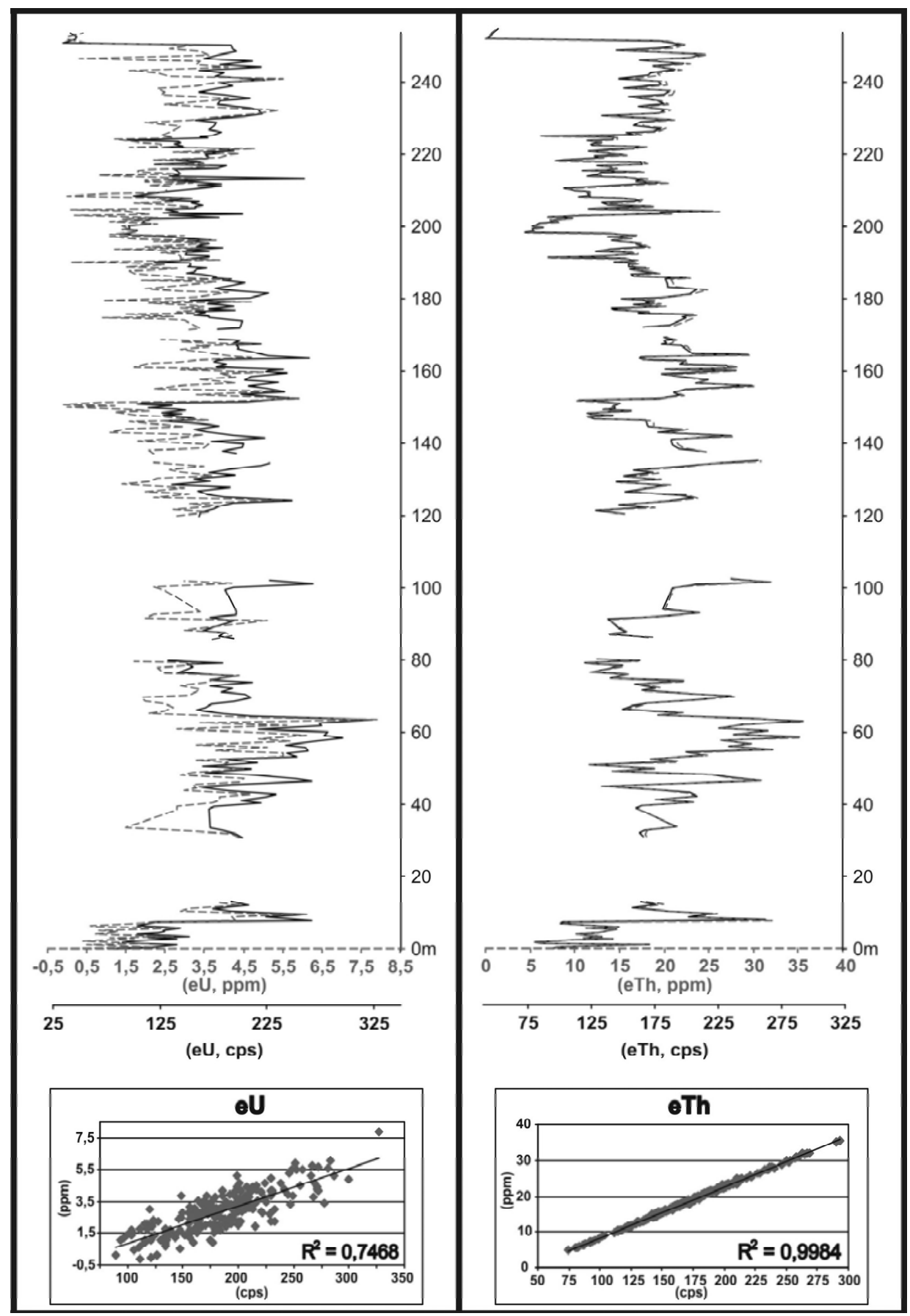

Figura $7 \mathbf{b}$ - Perfis gamaespectrométricos e gráficos de correlação (concentrações, linhas cheias versus cps, linhas tracejadas) dos canais eU e eTh na seção Tibagi.

são significativa, o que pode refletir problemas de calibração instrumental, mobilidade/dispersão do U, ou mesmo desequilíbrio radioativo. Por outro lado, os índices de correlação das demais variáveis foram considerados satisfatórios $(K \approx 0,9$; eTh $\approx 1,0$;
$\mathrm{CT}=1,0$ ), conforme as Figuras $7 \mathrm{a}$ e $7 \mathrm{~b}$.

Uma vez averiguada a precisão das leituras, efetuou-se à comparação dos perfis gamaespectrométrico e granulométrico, este último construído concomitantemente ao levantamento geo- 
físico. Como se pode observar na Figura 8 (localização na Fig. 4) 0 resultado é coerente, pois as camadas de folhelho do perfil granulométrico mostram picos de elevada radioatividade (setas cheias), enquanto níveis arenosos coincidem com baixos valores (setas tracejadas).

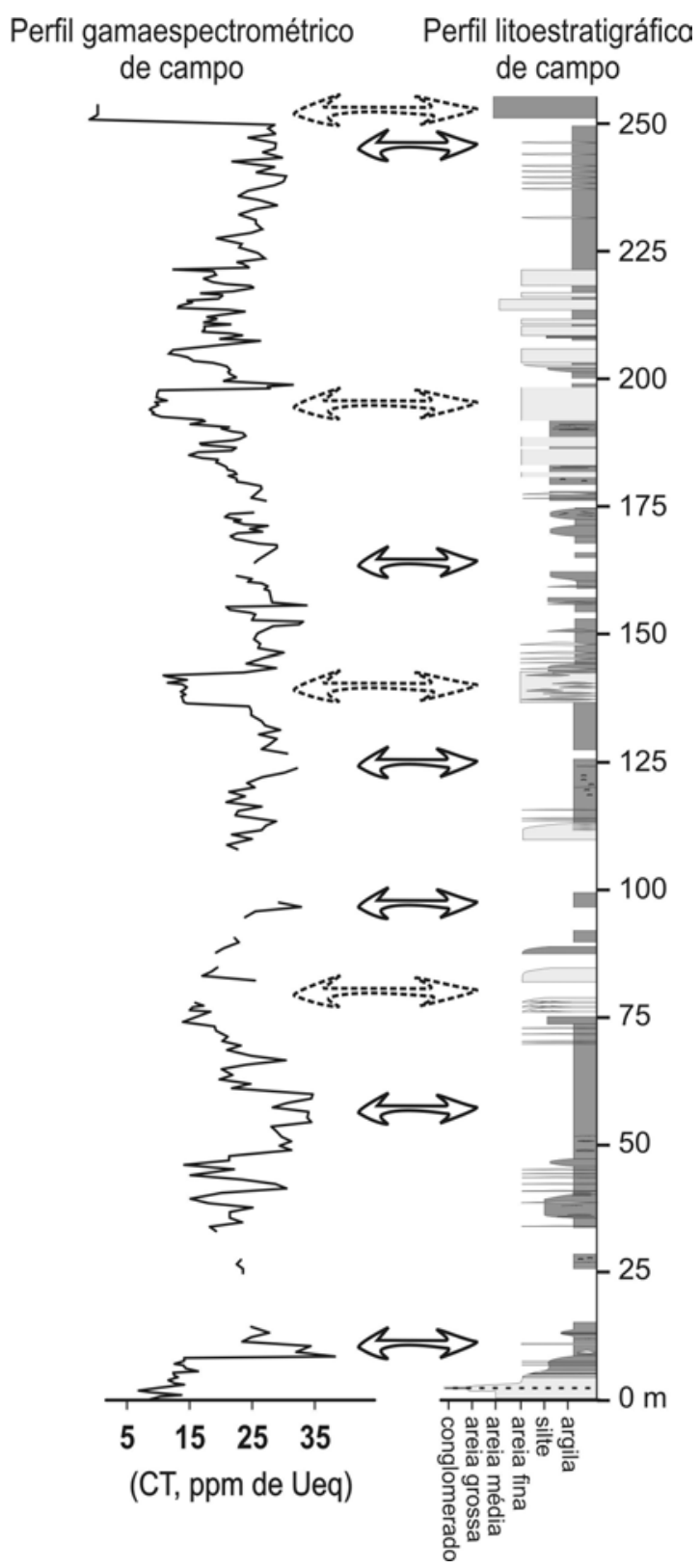

Figura 8 - Perfis gamaspectrométrico (esquerda) e litoestratigráfico (direita) da seção Tibagi indicando as respostas geofísicas de níveis argilosos (setas cheias) e arenosos (setas tracejadas).

Outro bom resultado foi derivado da comparação dos perfis gamaespectrométrico e de carbono orgânico total (COT), obtido por Bergamaschi (1999) na mesma seção (Fig. 9). Níveis estra- tigráficos com elevados teores de COT estariam relacionados a intervalos de preservação de matéria orgânica, reflexo de grande volume de deposição deste material e consequente redução de oxigênio (ambiente propício para retenção de U), que segundo 0 autor representariam superfícies de inundação máxima (SIM).

\section{Perfis de superfície - Estrada Tibati/Telêmaco Borba}

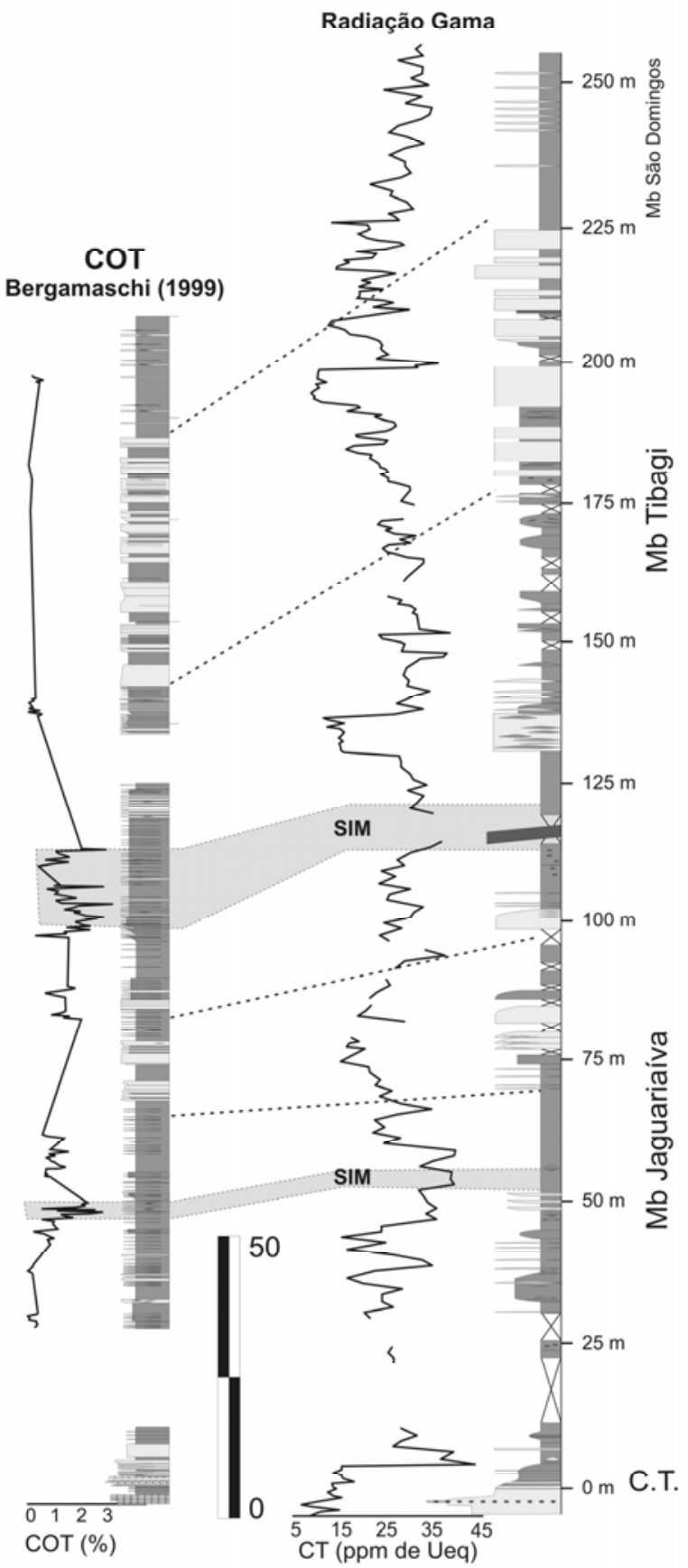

Figura 9 - Comparação dos perfis de carbono orgânico total (COT de Bergamaschi, 1999; esquerda) e gamaespectrométrico (Tibagi, direita), indicando as superfícies de inundação máxima (SIM). 


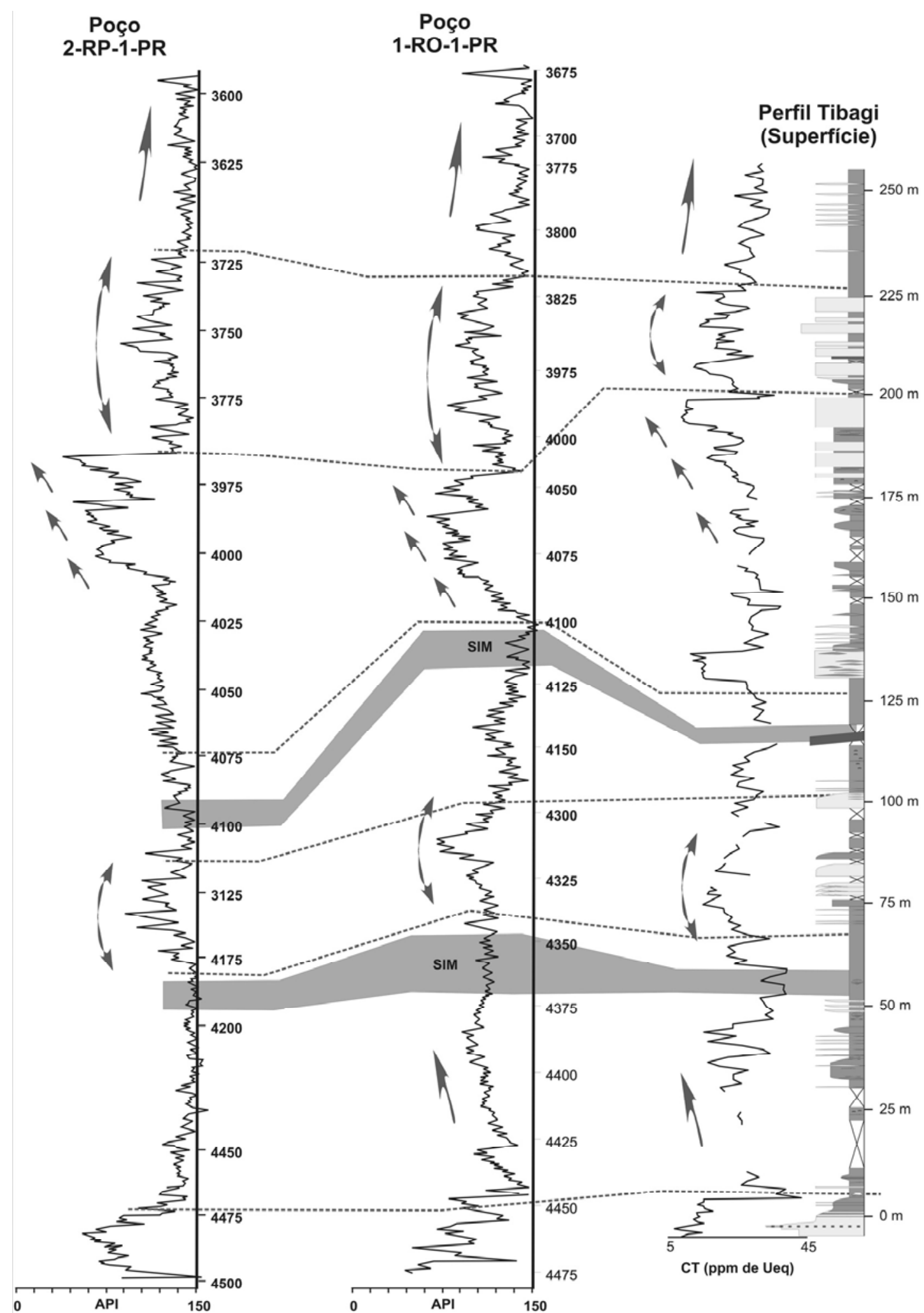

Figura 10 - Comparação do perfil Tibagi e de poços profundos. Notar a boa correspondência das tendências indicadas pelas setas (SIM = superfície de inundação máxima). 


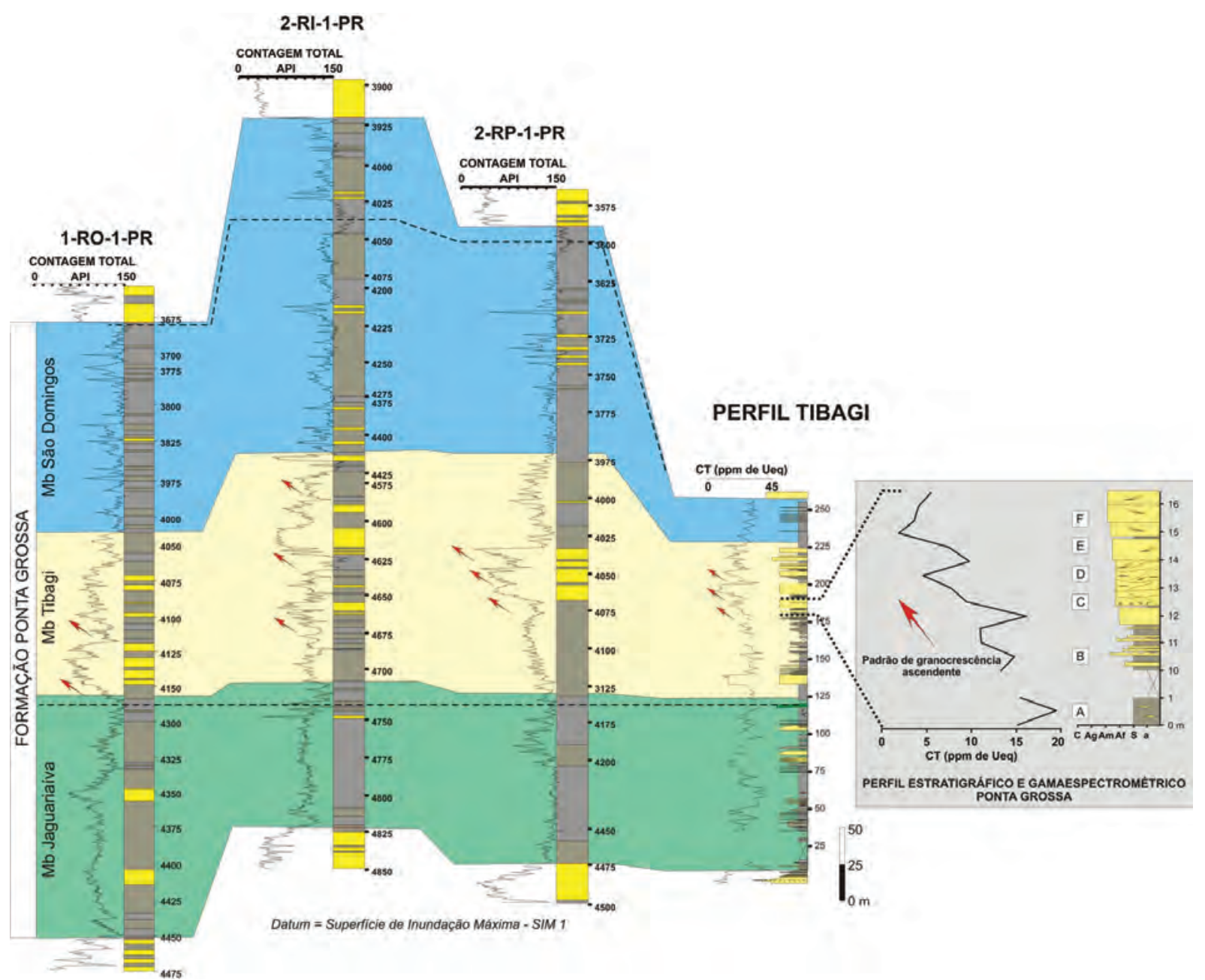

Figura 11 - Perfil gamaespectrométrico Ponta Grossa (direita) indicando granocrescência ascendente (seta vermelha) e sua correlação aos perfis Tibagi e de poços profundos (esquerda).

Valores elevados de radioatividade no perfil gamaespectrométrico são compatíveis com maior concentração de minerais de argila e matéria orgânica. As cargas negativas dispostas na superfície das argilas e da matéria orgânica são capazes de adsorver íons com cargas opostas (cátions), como U e Th, e podem ser substituídos uns pelos outros. Esse fenômeno é conhecido como troca de cátions, e ao conjunto das cargas negativas dáse 0 nome de capacidade de troca de cátions, CTC (Resende et al., 2002). Além dos minerais de argila, a matéria orgânica é de suma importância na dinâmica de adsorção de cátions. Alguns minerais de argila silicatada apresentam índices baixos de CTC (caulinita: $3-5 \mathrm{cmol}_{\mathrm{c}} . \mathrm{kg}^{-1}$; montmorillonita: $80-150 \mathrm{cmol}_{\mathrm{c}} . \mathrm{kg}^{-1}$ ) quando comparados a matéria orgânica, cuja CTC varia de 400 a $1000 \mathrm{cmol}_{\mathrm{c}} \mathrm{kg}^{-1}$ (Theng et al., 1989; Costa et al., 1999), o que explica o registro de valores elevados de radiação gama em correspondência a concentrações de matéria orgânica.
Por fim, foram cotejados os perfis gamaespectrométricos de superfície e os de poços profundos que atravessaram a Formação Ponta Grossa. Os resultados apresentados na Figura 10 (localização na Fig. 4) foram coerentes, uma vez que tendências similares (indicadas pelas setas) foram constatadas, as quais são representativas do empilhamento sedimentar e por isso são importantes para 0 entendimento da evolução estratigráfica da formação.

\section{Perfil Ponta Grossa}

Os resultados gamaespectrométricos do perfil Ponta Grossa (16 metros de espessura, localização na Fig. 4) se harmonizaram tanto às litologias dos afloramentos, quanto ao perfil Tibagi (Figs. 9 e 10) e aos dados de subsuperfície, como se observa na Figura 11. 0 perfil de campo se refere à fácies de barra de desembocadura deltaica do Membro Tibagi (Candido, 2007), composto por 
arenitos e pelitos intercalados, pouco bioturbados, formando um empilhamento, cuja tendência de incremento da fração areia em relação ao topo (granocrescência ascendente) é claramente refletida pelos dados de radiação gama (Fig. 11). Na base (A, Fig. 11), ocorrem siltitos argilosos micáceos que gradam para níveis arenosos no topo. A superfície acima dos níveis arenosos é caracterizada por marcas onduladas, sobre as quais se depositaram filmes argilosos de um centímetro de espessura (B, Fig. 11). Progressivamente, os níveis arenosos predominam, alcançando 20$40 \mathrm{~cm}$ de espessura, com base erosiva sobre as argilas (C, Fig. 11) e topo composto por material pelítico. No ápice da seção os arenitos não denotam mais intercalações argilosas e apresentam estratificação cruzada de pequeno porte e ótima maturidade mineralógica e textural (D, E, F, Fig. 11).

\section{CONCLUSÕES}

As principais conclusões podem ser assim resumidas: (i) a tendência de incremento gradativo da fração argila (granodecrescência ascendente) nas Camadas de Transição do perfil Arapoti, foi observada nos perfis de raios gama em superfície e subsuperfície; (ii) no Membro Jaguariaíva, os teores de carbono orgânico total (COT), relacionados às superfícies de inundação máxima (SIM), guardaram relação direta com 0 incremento da radiação gama registrada em superfície; (iii) no perfil Tibagi, se constatou boa correspondência dos dados gamaespectrométricos de superfície e a respectiva seção granulométrica ao longo dos 250 metros de exposição dos membros Jaguariaíva, Tibagi e São Domingos da Formação Ponta Grossa; (iv) ainda no perfil Tibagi se percebeu nítidas relações dos dados anteriores com as tendências gamaespectrométricas derivadas de poços profundos; (v) o Membro Tibagi, claramente mais arenoso, explicitou no perfil Ponta Grossa assinatura dos raios gama compatível a um padrão granocrescente ascendente, o qual, por sua vez, se harmonizou com segmento correspondente do perfil Tibagi e deste com os de poços profundos; (vi) o Membro São Domingos, representativo de possante intervalo pelítico da Formação Ponta Grossa, foi também bem caracterizado através de altas contagens; (vii) 0 emprego de gamaespectrometria de superfície, em correspondência à descrição de afloramentos e a dados de poços profundos, apontou para o estabelecimento de modelos análogos da Formação Ponta Grossa na Bacia do Paraná.

\section{AGRADECIMENTOS}

Os autores agradecem à Petróleo Brasileiro S.A. (Petrobras) pelo financiamento da pesquisa e pela Bolsa de Mestrado concedida a
AG Candido, além dos colegas Midori Fatori Deguchi, Fabio Gomes Machado e Thais Borba Santos pelo auxílio na aquisição dos dados de campo. Agradecem também aos revisores da Revista Brasileira de Geofísica pela análise crítica do manuscrito e pela sugestão de ampliar a revisão da literatura. FJF Ferreira agradece ao CNPq pela Bolsa de Produtividade em Pesquisa.

\section{REFERÊNCIAS}

AHMADI ZM \& COE AL. 1998. Methods for simulating natural gamma ray and density wireline logs from measurements on outcrop exposures and samples: examples from the Upper Jurassic, England. Geological Society, London, Special Publications, 136: 65-80.

AIGNER T \& BACHMANN GH. 1992. Sequence stratigraphic framework of the German Triassic. Sedimentary Geology, 80(1-2): 115-135.

AIGNER T, SCHAUER M, JUNGHANS W-D \& REINHARDT L. 1995. Outcrop gamma-ray logging and its applications: examples from the German Triassic. Sedimentary Geology, 100: 47-61.

AIGNER T, ASPRION U, HORNUNG J, JUNGHANS W-D \& KOSTREWA R. 1996. Integrated outcrop analogue studies for Triassic alluvial reservoirs: examples for southern Germany. Journal of Petroleum Geology, 19(4): 393-406.

AIGNER T, BRAUN S, PALERMO D \& BLENDINGER W. 2007. 3D geological modelling of a carbonate shoal complex: reservoir analogue study using outcrop data. First Break, 25: 65-72.

ALSHARHAN AS, NAIRN AEM \& MOHAMMED AA. 1993. Late Palaeozoic glacial sediments of the southern Arabian Peninsula: their lithofacies and hydrocarbon potential. Marine and Petroleum Geology, 10: 71-78.

ARYA AP. 1966. Fundamentals of nuclear physics. Allyn and Bacon, Boston, USA, $646 \mathrm{p}$.

ASSINE ML. 1996. Aspectos da estratigrafia das seqüências pré-carboníferas da Bacia do Paraná no Brasil. Tese (Doutorado em Geologia Sedimentar) - Universidade de São Paulo, São Paulo, 207 p.

ASSINE ML \& PETRI S. 1996. Seqüências e tratos deposicionais no Pré-Carbonífero da Bacia do Paraná, Brasil. In: Simpósio Sul-Brasileiro do Siluro-Devoniano, 1996, Ponta Grossa. Anais... Ponta Grossa, PMPG/UEPG/UFPR, 1996. p. 353-361.

ASSINE ML, SOARES PC \& MILANI EJ. 1994. Seqüências tectonosedimentares mesopaleozóicas da Bacia do Paraná. Revista Brasileira de Geociências, São Paulo, 24(2): 77-89.

ASSINE ML, PERINOTTO JAJ, FÚlFARO VJ \& PETRI S. 1998. Progradação deltáica Tibagi no Devoniano Médio da Bacia do Paraná. Revista Brasileira de Geociências, São Paulo, 28(2): 125-134.

BECEGATO VA \& FERREIRA FJF. 2005. Gamaespectrometria, resistividade elétrica e susceptibilidade magnética de solos agrícolas no noro- 
este do estado do Paraná. Revista Brasileira de Geofísica, Rio de Janeiro, 23(4): 371-405.

BERGAMASCHI S. 1999. Análise estratigráfica do Siluro-Devoniano (formações Furnas e Ponta Grossa) da sub-bacia de Apucarana, Bacia do Paraná, Brasil. Tese de Doutorado - Universidade de São Paulo, São Paulo, 167 p.

BESSA JL \& HESSELBO SP. 1997. Gamma-ray character and correlation of the Lower Lias, SW Britain. Proceedings of the Geologists' Association, 108: 113-129.

BETZLER C, PAWELLEK T, ABDULLAH M \& KOSSLER A. 2007. Facies and stratigraphic architecture of the Korallenoolith Formation in North Germany (Lauensteiner Pass, Ith Mountains). Sedimentary Geology, 194: $61-75$.

BIGARELLA JJ \& SALAMUNI R. 1967. Some paleogeographic features of the Brazilian Devonian. In: BIGARELLA JJ (Ed.). Problems in Brazilian Devonian Geology. Boletim Paranaense de Geociências, Curitiba, 21/22: 133-151.

BRACHERT TC, FORST MH, PAIS JJ, LEGOINHA P \& REIJMER JJG. 2003. Lowstand carbonates, highstand sandstones? Sedimentary Geology, 155: 1-12.

BROWN AL. 2002. Outcrop to subsurface stratigraphy of the Pennsylvanian Hermosa Group, southern Paradox Basin. PhD Dissertation, Graduate Faculty of the Louisiana State University and Agricultural and Mechanical College, USA, $181 \mathrm{p}$.

CALDWELL RL, BALDWIN WF, BARGAINER JD, BERRY JE, SALAITA GN \& SLOAN RW. 1963. Gamma-ray spectroscopy in well logging. Geophysics, 28(4): 617-632.

CANDIDO AG. 2007. Análise do potencial de ocorrências de reservatórios devonianos na porção profunda da Bacia do Paraná baseada na caracterização estratigráfica do Membro Tibagi, Formação Ponta Grossa. Dissertação (Mestrado em Geologia Exploratória) - Universidade Federal do Paraná, Curitiba, 124 p.

CANDIDO AG \& ROSTIROLLA SP. 2007. Análise de fácies e revisão da estratigrafia de seqüências da Formação Ponta Grossa, Bacia do Paraná - ênfase nos arenitos do Membro Tibagi. Boletim de Geociências da Petrobras, Rio de Janeiro, 15(1): 45-62.

CARVALHO JS, RUDNITZKI ID, ARAUJO RLC, NOGUEIRA ACR, ARAUJO FM, CONCEIÇÃO DA \& PERES TA. 2006. Levantamento gamaespectrométrico sobre exposições de sedimentos da Formação Prosperança, na borda norte da bacia do Amazonas. In: Congresso Brasileiro de Geologia, 43., 2006, Aracaju. Anais... Aracaju: SBG, 2006, p. 118.

CHIOZZI P, PASQUALE V, VERDOYA M \& MINATO S. 2003. Gamma-ray activity in the volcanic islands of the Southern Tyrrhenian Sea. Journal of Environmental Radioactivity, 67: 235-246.
CLARKE JM. 1913. Fósseis devonianos do Paraná. Monografias do Serviço Geológico e Mineralógico do Brasil, Rio de Janeiro, 1: 353 p.

COLLINS LB, READ JF, HOGARTH JW \& COFFEY BP. 2006. Facies, outcrop gamma ray and $\mathrm{C}-0$ isotopic signature of exposed Miocene subtropical continental shelf carbonates, North West Cape, Western Australia. Sedimentary Geology, 185: 1-19.

COSTA ACS, TORINO CA \& RAKJG. 1999. Capacidade de troca catiônica dos colóides orgânicos e inorgânicos de latossolos do Estado do Paraná. Acta Scientiarum, Maringá, 21(3): 491-496.

DAEMON RF, QUADROS LP \& SILVA LC. 1967. Devonian palynology and biostratigraphy of the Paraná Basin. Boletim Paranaense de Geociências, Curitiba, 21/22: 99-132.

DOVETON JH \& MERRIAM DF. 2004. Borehole petrophysical chemostratigraphy of Pennsylvanian black shales in the Kansas subsurface. Chemical Geology, 206: 249-258.

DUARTE 00. 2003. Dicionário enciclopédico inglês-português de geofísica e geologia. Sociedade Brasileira de Geofísica - SBGf, 2 ed., Rio de Janeiro, $352 \mathrm{p}$.

DYPVIK H \& ERIKSEN DØ. 1983. Natural radioactive of clastic sediments and the contributions of $U$, Th and K. Journal of Petroleum Geology, 5(4): 409-416.

ELLIS DV \& SINGER JM. 2008. Well Logging for Earth Scientists. Springer, The Netherlands, 2 ed., $692 \mathrm{p}$.

EVANS R, MORY AJ \& TAIT AM. 2007. An outcrop gamma ray study of the Tumblagooda Sandstone, Western Australia. Journal of Petroleum Science and Engineering, 57: 37-59.

FAURE G. 1986. Principles of isotope geology. New York, Wiley, 2 ed., $589 p$.

FERREIRA FJF. 1982a. Alinhamentos estruturais-magnéticos da região centro-oriental da Bacia do Paraná e seu significado tectônico. In: Bacia do Paraná - Reavaliação da potencialidade e prospectividade em hidrocarbonetos. Consórcio CESP-IPT (Paulipetro), São Paulo, p. 143-166.

FERREIRA FJF. 1982b. Integração de dados aeromagnéticos e geológicos: configuração e evolução tectônica do Arco de Ponta Grossa. Dissertação (Mestrado em Geologia Geral e de Aplicação) - Universidade de São Paulo, São Paulo, 170 p.

FERREIRA FJF, MORAES RAV, FERRARI MP \& VIANNA RB. 1981. Contribuição ao estudo do Alinhamento Estrutural de Guapiara. In: Simpósio Regional de Geologia, 3, 1981, Curitiba. Anais... Curitiba: SBG, 1981. p. 226-240.

FILER JK. 2002. Late Frasnian sedimentation cycles in the Appalachian basin - possible evidence for high frequency eustatic sea-level changes. Sedimentary Geology, 154: 31-52.

FORST MH, BRACHERT TC \& PAIS J. 2000. High-resolution correlation of coastal cliff sections in the Lagos-Portimão Formation (Lower-Middle 
Miocene, central Algarve, Portugal). Ciências da Terra (UNL), Lisboa, 14: 289-296.

FÚlFARO VJ, SAAD AR, SANTOS MV \& VIANNA RB. 1982. Compartimentação e evolução tectônica da Bacia do Paraná. Revista Brasileira de Geociências, São Paulo, 12(4): 233-256.

GEHRING I. 2004. The use of grain-size dependent magnetic susceptibility and gamma-ray measurements for the detailed reconstruction of volcanostratigraphy: The case of La Fossa di Vulcano, S. Italy. Journal of Volcanology and Geothermal Research, 138: 163-183.

HADLEY MJ, RUFFELL A \& LESLIE AG. 2000. Gamma-ray spectroscopy in structural correlations: an example from the Neoproterozoic Dalradian succession of Donegal (NW Ireland). Geological Magazine, 137(3): 319333.

HLADIL J, BOSAK P, SLAVIK L, CAREW JL, MYLROIE JE \& GERSL M. 2003. Early diagenetic origin and persistence of gamma-ray and magnetosusceptibility patterns in platform carbonates: comparison of Devonian and Quaternary sections. Physics and Chemistry of the Earth, 28: 719727.

HODSON G, FERTL WH \& HAMMACK GW. 1976. Formation evaluation in Jurassic sandstone in the northern North Sea area. The Log Analyst, 17(1): 22-32.

HORNUNG J \& AIGNER T. 1999. Reservoir and aquifer characterization of fluvial architectural elements: Stubensandstein, Upper Triassic, southwest Germany. Sedimentary Geology, 129: 215-280.

HORNUNG J \& AIGNER T. 2002a. Reservoir architecture in a terminal alluvial plain: an outcrop analogue study (Upper Triassic Southern Germany). Part I: Sedimentology and Petrophysics. Journal of Petroleum Geology, 25(1): 3-30.

HORNUNG J \& AIGNER T. 2002b. Reservoir architecture in a terminal alluvial plain: an outcrop analogue study (Upper Triassic Southern Germany). Part II: Cyclicity, Controls and Models. Journal of Petroleum Geology, 25(1): 151-178.

KAPLAN I. 1962. Fisica Nuclear. Aguilar, Madrid, 728 p.

KOEHRER BS, HEYMANN C, PROUSA F \& AIGNER T. 2010. Multiplescale facies and reservoir quality variations within a dolomite body - Outcrop analog study from the Middle Triassic, SW German Basin. Marine and Petroleum Geology, 27: 386-411.

KOSTIC B \& AIGNER T. 2004. Sedimentary and poroperm anatomy of shoal-water carbonates (Muschelkalk, South-German Basin): an outcrop-analogue study of inter-well spacing scale. Facies, 50: 113131.

LANGE FW. 1967. Biostratigraphic subdivision and correlation of the Devonian in the Paraná Basin. Boletim Paranaense de Geociências, Curitiba, 21/22: 63-98.
LANGE FW \& PETRI S. 1967. The Devonian of the Paraná Basin. Boletim Paranaense de Geociências, Curitiba, 21/22: 5-55.

LÜNING S \& KOLONIC S. 2003. Uranium spectral gamma-ray response as a proxy for organic richness in black shales: applicability and limitations. Journal of Petroleum Geology, 26(2): 153-174.

LÜNING S, LOYDELL DK, SUTCLIFFE 0, SALEM AA, ZANELLA E, CRAIG J \& HARPEL DAT. 2000a. Silurian-Lower Devonian black shales in Morocco: which are the organically richest horizons? Journal of Petroleum Geology, 23(3): 293-311.

LÜNING S, CRAIG J, LOYDELL DK, STORCH P \& FITCHES B. 2000b. Lower Silurian 'hot shales' in North Africa and Arabia: regional distribution and depositional model. Earth-Science Reviews, 49: 121-200.

LÜNING S, WENDT J, BELKA Z \& KAUFMANN B. 2004. Temporal-spatial reconstruction of the early Frasnian (Late Devonian) anoxia in NW Africa: new field data from the Ahnet Basin (Algeria). Sedimentary Geology, 163: 237-264.

LÜNING S, SHAHIN YM, LOYDELL D, AL-RABI HT, MASRI A, TARAWNEH B \& KOLONIC S. 2005. Anatomy of a world-class source rock: Distribution and depositional model of Silurian organic-rich shales in Jordan and implications for hydrocarbon potential. AAPG Bulletin, 89(10): 1397-1427.

MAACK R. 1950-51. Vestígios pré-devonianos de glaciação e a seqüência de camadas devonianas no Estado do Paraná. Arquivos de Biologia e Tecnologia (IBPT), 5-6: 197-230.

MARTINIUS AW, GEEL CR \& ARRIBAS J. 2002. Lithofacies characterization of fluvial sandstones from outcrop gamma-ray logs (Loranca Basin, Spain): the influence of provenance. Petroleum Geoscience, 8(1): 5162.

MATHIS GL. 1987. Smoothing spectral gamma logs: A simple but effective technique. Geophysics, 52(3): 363-367.

MILANI EJ. 1997. Evolução tectono-estratigráfica da Bacia do Paraná e seu relacionamento com a geodinâmica fanerozóica do Gondwana Sulocidental. Tese de Doutorado - Universidade Federal do Rio Grande do Sul, Porto Alegre, 2v, $255 \mathrm{p}$.

MILANI EJ. 2004. Comentários sobre a origem e a evolução tectônica da Bacia do Paraná. In: MANTESSO-NETO V, BARTORELLI A, CARNEIRO CDR \& BRITO NEVES BB (Eds.). Geologia do continente sul-americano: evolução da obra de Fernando Flávio Marques de Almeida, São Paulo, Beca. p. 265-279.

MILANI EJ, MELO JHG, SOUZA PA, FERNANDES LA \& FRANÇA AB. 2007. Bacia do Paraná. In: MILANI EJ, RANGEL HD, BUENO GV, STICA JM, WINTER WR, CAIXETA JM \& PESSOA NETO OC (Eds.). Bacias Sedimentares Brasileiras - Cartas Estratigráficas. Boletim de Geociências da Petrobras, Rio de Janeiro, 15(2): 265-287. 
NORTH CP \& BOERING M. 1999. Spectral gamma-ray logging for facies discrimination in mixed fluvial-eolian successions: A cautionary tale. AAPG Bulletin 83(1): 155-169.

NORTHFLEET AA, MEDEIROS RA \& MÜHLMANN H. 1969. Reavaliação dos dados geológicos da Bacia do Paraná. Boletim Técnico da Petrobras, Rio de Janeiro, 12(3): 291-346.

OLIVEIRA EP. 1927. Geologia e recursos minerais do estado do Paraná. Monografias do Serviço Geológico e Mineralógico do Brasil, Rio de Janeiro, 6: $172 \mathrm{p}$.

PAWELLEK T \& AIGNER T. 2003. Stratigraphic architecture and gamma ray logs of deeper ramp carbonates (Upper Jurassic, SW Germany). Sedimentary Geology, 159: 203-240.

PAWELLEK T \& AIGNER T. 2004. Dynamic stratigraphy as a tool in economic mineral exploration: ultra-pure limestones (Upper Jurassic, SW Germany). Marine and Petroleum Geology, 21: 499-516.

PEREIRA E. 2000. Evolução tectono-sedimentar do intervalo Ordoviciano-Devoniano da Bacia do Paraná com ênfase BA sub-bacia de Alto Garças e no Paraguai Oriental. Tese (Doutorado em Geologia Sedimentar) - Universidade de São Paulo, São Paulo, 276 p.

PEREIRA E \& BERGAMASCHI S. 1996. Estudo da evolução tectonosedimentar das seqüências ordoviciana, siluriana e devoniana nas subbacias Apucarana e Alto Garças, Bacia do Paraná, Gondwana Ocidental. In: Simpósio Sul-Brasileiro do Siluro-Devoniano, 1996, Ponta Grossa. Anais... Ponta Grossa, PMPG/UEPG/UFPR, 1996. p. 219-238.

PETRI S. 1948. Contribuição ao estudo do Devoniano Paranaense. Rio de Janeiro: Departamento Nacional da Produção Mineral, 125 p. (Brasil. Departamento Nacional da Produção Mineral. Divisão de Geologia e Mineralogia. Boletim 129).

RAMOS NA. 1970. Aspectos paleo-estruturais da Bacia do Paraná e sua influência na sedimentação. Boletim Técnico da Petrobras, Rio de Janeiro, 13(3/4): 85-93.

RESENDE M, CURI N, REZENDE SB \& CORRÊA GF. 2002. Pedologia: bases para distinção de ambientes. Viçosa, MG, NEPUT, 338 p.

RHODES DF \& MOTT WE. 1966. Quantitative interpretation of gammaray spectral logs. Geophysics, 31(2): 410-418.

RIDER MH. 1990. Gamma-ray log shape used as a facies indicator: critical analysis of an oversimplified methodology. In: HURST A, LOVELL MA \& MORTON AC (Eds.). Geological Applications of Wireline Logs. Geological Society Special Publication, London: The Geological Society, no. 48: p. 27-37.

RUDNITZKI ID, AMARAL FR, CARVALHO JS \& ARAUJO RLC. 2007. Gamaespectrometria aplicada ao diagnóstico faciológico-estratigráfico de exposições da Formação Prosperança, em Presidente Figueiredo (AM). In: Simpósio de Geologia da Amazônia, 10., 2007, Porto Velho. Anais... Porto Velho: SBG, 2007, p. 378-380.
RUF M \& AIGNER T. 2004. Facies and poroperm characteristics of a carbonate shoal (Muschelkalk, South German Basin): a reservoir analogue investigations. Journal of Petroleum Geology, 27(3): 215-239.

RUHOVETS N \& FERTL WH. 1982. Digital shaly sand analysis based on Waxman-Smits model and log-derived clay typing. The Log Analyst, 23(3): 7-23.

SAUNDERS DF, TERRY SA \& THOMPSON CK. 1987. Test of National Uranium Resource Evaluation gamma-ray spectral data in petroleum reconnaissance. Geophysics, 52(11): 1547-1556.

SCHMOKER JM. 1981. Determination of organic-matter content of Appalachian Devonian shales from gamma-ray logs. AAPG Bull. 65: 12851298.

SCHNYDER J, RUFFELL A, DECONINCK J-F \& BAUDIN F. 2006. Conjunctive use of spectral gamma-ray logs and clay mineralogy in defining late Jurassic - early Cretaceous palaeoclimate change (Dorset, U.K.). Palaeogeography, Palaeoclimatology, Palaeoecology, 229: 303-320.

SCOTT JH. 1963. Computer analysis of gamma-ray logs. Geophysics, 28(3): 457-465.

SCOTT JH, DODD PH, DROULLARD RF \& MUDRA PJ. 1961. Quantitative interpretation of gamma-ray logs. Geophysics, 26(2): 182-191.

SEGESMAN FF. 1980. Well-logging method. Geophysics, 45(11): 1667-1684.

SHERIFF RE. 1999. Encyclopedic dictionary of exploration geophysics. Society of Exploration Geophysicists - SEG, Geophysical References Series, 1, Tulsa, $384 \mathrm{p}$.

SLATT RM, JORDAN DW, D'AGOSTINO AE \& GILLESPIE RH. 1992. Outcrop gamma-ray logging to improve understanding of subsurface well log correlations. Geological Society, London, Special Publications, 65: 3-19.

SLATT RM, BORER JM, HORN BW, AL-SIYABI HA \& PIETRASZEK SR. 1995. Outcrop gamma-ray logging applied to subsurface petroleum geology. Mountain Geologist, 32(4): 81-94.

SNYDER DD \& FLEMING DB. 1985. Well logging - A 25-year perspective. Geophysics, 50(12): 2504-2529.

SOARES PC. 1992. Tectônica sinsedimentar cíclica na Bacia do Paraná: controles. Tese (Professor Titular), Departamento de Geologia, Universidade Federal do Paraná, 148 p.

SOARES PC, LANDIM PMB \& FÚLFARO VJ. 1978. Tectonic cycles and sedimentary sequences in the Brazilian intracratonic basins. Geological Society of America Bulletin, Boulder, 89(2): 181-191.

SVENDSEN JB \& HARTLEY NR. 2001. Comparison between outcropspectral gamma ray logging and whole rock geochemistry: implications for quantitative reservoir characterisation in continental sequences. Marine and Petroleum Geology, 18: 657-670. 
SZURLIES M, BACHMANN GH, MENNING M, NOWACZYK NR \& KÄDING, KC. 2003. Magnetostratigraphy and high-resolution lithostratigraphy of the Permian-Triassic boundary interval in Central Germany. Earth and Planetary Science Letters, 212: 263-278.

THENG BKG, TATE KR \& SOLLINS P. 1989. Constituents of organic matter in temperate and tropical soils. In: COLEMAN DC, OADES JM \& UEHARA G (Eds.). Dynamics of soil organic matter in tropical ecosystems. Honolulu: NifTAL Project, p. 5-32.

ULBRICHT HHGJ, ULBRICHT MNC, FERREIRA FJF, ALVES LS, GUIMARÃES GB \& FRUCHTING A. 2009. Levantamentos Gamaespectrométricos em Granitos Diferenciados. I: Revisão da Metodologia e do Comportamento Geoquímico dos Elementos K, Th e U. Geologia USP, Série Científica, São Paulo, 9(1): 33-53.

VENNIN E, VAN BUCHEM FSP, JOSEPH P, GAUMET F, SONNENFELD M, REBELLE M, JEMIA HFB, \& ZIJLSTRA H. 2003. A 3D outcrop analo- gue model for Ypresian nummulitic carbonate reservoirs: Jebel Ousselat, northern Tunisia. Petroleum Geoscience, 9: 145-161.

WAHL JS. 1983. Gamma-ray logging. Geophysics, 48(2): 1536-1550.

WEHR MR \& RICHARDS Jr. JA. 1965. Física do átomo. Livro Técnico e Editora da Universidade de São Paulo, Rio de Janeiro, 467 p.

ZALÁN PV, WOLFF S, CONCEIÇÃO JCJ, ASTOLFI MAM, VIEIRA IS, APPI VT \& ZANOTTO A0. 1987. Tectônica e sedimentação da Bacia do Paraná. In: Simpósio Sul-Brasileiro de Geologia, 3, Curitiba. Atas... SBG, 1: p. 441-473.

ZALÁN PV, WOLFF S, ASTOLFI MAM, VIEIRA IS, CONCEIÇÃO JCJ, APPI VT, SANTOS NETO EV, CERQUEIRA JR \& MARQUES A. 1990. The Paraná Basin, Brazil. In: LEIGHTON MW, KOLATA DR, OLTZ DF \& EIDEL JJ (Eds.). Interior cratonic basins. Tulsa: American Association of Petroleum Geologists, AAPG Memoir, 51: 681-708.

\section{NOTAS SOBRE OS AUTORES}

Francisco José Fonseca Ferreira é Geólogo (UFPE-1970), Especialista em Geofísica Aplicada (UFBA-1974), Mestre e Doutor em Ciências (USP-1982; USP-1991), com atuação profissional na CPRM (1972-1980) e no IPT (1980-1990). A partir de 1998 coordena o Laboratório de Pesquisas em Geofísica Aplicada - LPGA/UFPR, onde desenvolve pesquisas multidisciplinares aplicadas ao ambiente, à exploração mineral e de águas subterrâneas. Atualmente é Bolsista de Produtividade em Pesquisa do CNPq e Professor Associado do Departamento de Geologia da UFPR, onde ministra disciplinas de geofísica aplicada nos cursos de graduação e pós-graduação.

Ary Gustavo Candido é Geólogo (UFPR-2005) e Mestre em Geologia Exploratória (UFPR-2007). Atualmente trabalha na Unidade de Operações de Exploração e Produção da Bacia de Campos/Gerência de Avaliação de Blocos e Interpretação Geológica e Geofísica (Petrobras).

Sidnei Pires Rostirolla é Geólogo (UFPR-1989), Mestre em Geologia (UFOP-1991) e Doutor em Geociências (Unesp-1996). Foi Professor Associado do Departamento de Geologia da UFPR, onde ministrou as seguintes disciplinas: análise de bacias, fotogeologia, geologia do petróleo, recursos energéticos e reservatórios fraturados nos cursos de graduação e pós-graduação. Entre 2002 e 2008 coordenou o Laboratório de Análise de Bacias e Petrofísica - LABAP/UFPR, onde desenvolveu pesquisas multidisciplinares aplicadas à análise de bacias e exploração de hidrocarbonetos. Atualmente trabalha na Vale. 